\title{
Evaluating Graduated Response
}

\author{
Rebecca Giblin*
}

\section{PROMISES \& AIMS}

The war against online copyright infringement has been fought on a number of different fronts - via litigation against the peer-to-peer ("P2P") software providers who enabled it, the end users who engaged in it and, most recently, against the ISPs who provide the infrastructure that permits the data to flow. This last strategy has seen powerful content interests forcefully lobbying governments and ISPs worldwide to adopt so-called "graduated responses." The message has been that content owners shouldn't be responsible for policing infringement. In the view of the International Federation of the Phonographic Industry (IFPI):

[A]ctions against individual uploaders are onerous and expensive and we shouldn't have to be taking them. That job should not be ours-it should be done by the gatekeepers of the web, the Internet Service Providers (ISPs), who unquestionably

* Senior Visiting Scholar, U.C. Berkeley School of Law, 2013; faculty member, Monash University Law School; member, Monash Commercial Law Group. Special thanks to Professor Pamela Samuelson for generously supporting my work by sponsoring my visit to Berkeley, to the Berkeley Center for Law \& Technology for hosting a seminar about the paper in November 2013, and to the attendees for sharing their commentary and insights. Further thanks to Christophe Geiger and CEIPI who hosted in me in Strasbourg while I was finalizing the French sections of the paper, and to François Petitjean, Leanne O'Donnell and Gwen Hinze who generously read and commented on drafts. I must also acknowledge the contributions of the many wonderful folk who helped me to identify or track down sources, or who provided translations: Johnny Ryan, Eoin O’Dell, Andres Guadamuz, Lilian Edwards, Adrienne Charmet-Alix, Joseph Valente, Philippe Laurent, Alain Strowel, Rick Shera, Susan Chalmers, James Firth, Ronan Lupton, Nicolas Jondet, Heesob Nam, Glyn Moody, Heli Askola and Justices Peter Charleton and David Harvey. I also acknowledge the contribution of Paul Bradley, Director of Corporate Affairs for the eircom Group, who spoke with me via phone in September 2012 about various elements of the Irish regime. Finally, I am grateful to Professors Susy Frankel and Daniel Gervais, organizers of the "Evolution and Equilibrium: Copyright This Century" conference (Wellington, Nov. 2012), and to the conference participants, especially Professor Jane Ginsburg, for their comments and suggestions on an earlier work from which this paper has been developed. Due to the many languages involved and the sometimes lack of official translations, in some places trusted secondary sources have been used to bolster primary sources. Copies of electronic resources referred to within this chapter are on file with the author. Medium neutral citations have been provided to facilitate open access to source materials where possible. The law and other developments discussed within this paper are current to Sep. 1, 2013. The hypothesis and analysis in this piece are new, but some of the descriptions of the various graduated response schemes are drawn from previous work written by the author. See Rebecca Giblin, Beyond Graduated Response, in The Evolution and Equilibrium of Copyright in the Digital Age (Susy Frankel \& Daniel Gervais, eds., Cambridge University Press forthcoming 2014); Rebecca Giblin, Was the High Court in iiNet Right to be Chary of a Common Law Graduated Response?, MEDIA \& ARTS L. REV. (forthcoming 2013); Rebecca Giblin, On the (New) New Zealand Graduated Response Law (and Why It's Unlikely to Achieve its Aims) 62(4) TeLECOMMS. J. AusTL. 54.1 (2012). 
have the technical means to deal with copyright infringement, if only they would take responsibility for doing so. ${ }^{1}$

Big promises have been made about the effects graduated response would have on end user infringement. In its 2007 Annual Digital Music Report, IFPI claimed that "[w]ith cooperation from ISPs, [it] could make huge strides in tackling content piracy globally" and argued that "[d]isconnection of serious copyright offenders by ISPs is the easiest and most practical response to illegal file-sharing."2 Its view was that "[d]isconnection of service for serious infringers should become the speeding fine or the parking ticket of ISP networks."3 The message in the announcement of its 2008 report was the same: "ISP cooperation, via systematic disconnection of infringers and the use of filtering technologies, is the most effective way copyright theft can be controlled."4 The Motion Picture Association of America (MPAA) has similarly claimed that "[a] variety of approaches, including graduated response policies and technological tools, can meaningfully contribute to thwarting unlawful conduct online." 5

These promises have been accepted in a number of jurisdictions around the world. Five countries-France, New Zealand, Taiwan, South Korea, and the UKhave enacted public laws which place some degree of responsibility on ISPs to police their users' infringements. The first four have all been operational for some time, but the details of the UK arrangement are still being hammered out. In addition to these public graduated response laws, private arrangements between some rights holders and some ISPs have been reached in a few jurisdictions in an effort to achieve the same end result. The most notable of these operate in Ireland and in the U.S. This Article only considers systems that involve some potential penalty or consequence for repeated infringement. So-called "notice-notice" schemes, where ISPs compulsorily or voluntarily forward infringement allegations to their customers but no penalty follows, are outside the scope of this Article.

This Article seeks to identify the effects of the various graduated response schemes around the world and evaluate the extent to which they are achieving their aims. This is far easier said than done. Influential rights holders have repeatedly claimed that graduated response really does work. For example, IFPI has declared that graduated responses "have been effective where they have been introduced,"6 and the MPAA has announced that graduated response strategies "have proven to

1. Int'l Fed'n Phonographic Indus., IFPI:07 Digital Music Report 3 (2007), http://www.ifpi.org/ content/library/digital-music-report-2007.pdf.

2. Id. at 19 .

3. Id. at 3 .

4. Int'l Fed'n of the Phonographic Indus., IFPI publishes Digital Music Report 2008 (Jan. 24, 2008), http://www.ifpi.org/content/section_resources/dmr2008.html.

5. Letter from the Motion Picture Ass'n of Am., Inc. in Response to the Workshop on the Role of Content in the Broadband Ecosystem (Oct. 30, 2009), available at http://www.wired.com/images_ blogs/threatlevel/2009/11/mpaafiltering.pdf.

6. Int'l Fed'n Phonographic Indus., IFPI Digital Music Report 2013, at 30 (2013), http://www.ifpi.org/content/library/DMR2013.pdf. 
be successful in various contexts around the world." 7 However, judging the "success" or "effectiveness" of any copyright policy is a challenging exercise due to longstanding and fundamental disagreements about which factors success should be measured against. What is copyright law actually seeking to achieve?

There has never been universal agreement about what copyright law's aims are, or even about what they should be. Multiplicities of theoretical and pragmatic considerations are part of the policy mix in any jurisdiction seeking to reform its copyright law. In recognition of that reality, this Article considers the extent to which each graduated response law is achieving the three aims that are most commonly used to justify the grant and expansion of copyright.

The first evaluation point will be the extent to which global graduated response reduces infringement. The suggestion that reduced infringement in and of itself is a proper aim of the copyright law is one that has been made often by major global rights holders. Thus, when IFPI declared that graduated responses "have been effective where they have been introduced," the evidence it provided in support was a claim of reduced use of P2P services in France and New Zealand, and a fall in cyberlocker usage in South Korea. ${ }^{8}$ Although it sought to link the reduction in South Korea with an increase in the legitimate market, the claims about New Zealand and France equated reduced infringement with "effectiveness" without addressing whether that reduction would translate to higher sales, increased distribution, more creation or higher quality creative output. ${ }^{9}$ In August 2013, the U.S. Patent \& Trademark Office (USPTO) invited public submissions to help it determine whether voluntary initiatives such as the U.S. graduated response scheme have helped reduce infringement. ${ }^{10}$ One specific question it asked was "[h]ow should 'effectiveness' of cooperative voluntary initiatives be defined?" The Recording Industry Association of America (RIAA) argued that, to measure effectiveness, the USPTO should begin by identifying the intended goal of each voluntary initiative. ${ }^{11}$ It then recommended that the Office "consider whether or not the intended goal, if achieved, would likely be useful to deter online infringement." 12 This seemed to suggest that reduced infringement is a proper aim in and of itself — or at least the one that should be given the greatest weight.

7. See, e.g., Motion Picture Ass'n of Am., Trade Barriers to Exports of U.S. Filmed Entertainment viii (Oct. 2010), http://www.mpaa.org/resources/69721865-ac82-4dc4-88ec01ee84c651a1.pdf; Letter from Motion Picture Ass'n of Am. in Response to Request of the Dep't of Commerce for Public Comments: Global Free Flow of Information on the Internet 8 (Dec. 6, 2010), available at $\mathrm{http} / /$ www.ntia.doc.gov/files/ntia/comments/100921457-0457-01/attachments/international $\%$ 20filingMPAA.pdf.

8. Int'l Fed. Phonographic Indus., supra note 6, at 30.

9. Id.

10. Request of the USPTO. for Public Comments: Voluntary Best Practices Study (Jun. 20, 2013), available at https://www.federalregister.gov/articles/2013/06/20/2013-14702/request-of-theunited-states-patent-and-trademark-office-for-public-comments-voluntary-best.

11. Letter from the Recording Indus. Ass'n of Am. in Response to Request of the USPTO for Public Comments: Voluntary Best Practices Study 2 (Aug. 19, 2013), available at http://www.uspto. gov/ip/officechiefecon/PTO-C-2013-0036.pdf.

12. Id. 
The argument that copyright laws should aim to reduce infringement is often cloaked in the rhetoric of property and theft. One example of this is the MPAA's long-running "Piracy_it's a crime" campaign, which features the words:

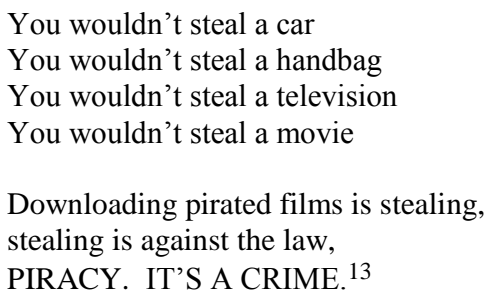

By using this rhetoric, the MPAA can be seen as relying on a right-based justification that is analogous to the one that underpins the natural rights theory. Natural rightists see authors as acquiring property rights in their works "by virtue of the mere act of creation," with the "corollary that nothing is left to the law apart from formally recognizing what is already inherent in the "very nature of things." 14 That is, "natural rights arguments are less concerned with regulatory techniques to promote social, cultural and economic goals than with a belief that copyright ought to exist because it is proper and correct for it to do so."15 As Martin Senftleben explains,

[t]he natural law argument supporting authors' rights appeals to feelings of rightness and justice. As it is the author who spends time and effort on the creation of a new work of the intellect, it is deemed justified to afford him the opportunity of reaping the fruit of his labour. ${ }^{16}$

The natural rights approach has traditionally driven copyright policymaking in the civil law tradition. ${ }^{17}$ However, as Senftleben and Alfred C. Yen have both demonstrated, it has also influenced lawmaking in historically utilitarian jurisdictions such as the U.S. ${ }^{18}$ In recognition of the fact that reducing infringement is regularly claimed as an important aim of copyright law, this Article will analyze the extent to which graduated response is succeeding in doing so.

The second point of evaluation is the extent to which graduated response maximizes the size of the legitimate market. This assumes that reduced infringement may be a proper aim in and of itself, but only to the extent to which

13. Motion Picture Ass'n of Am., Piracy It's a Crime (2007), available at https://www.youtube. $\mathrm{com} /$ watch? $\mathrm{v}=\mathrm{HmZm} 8 \mathrm{vNHBSU}$.

14. Martin Senftleben, Copyright, Limitations and the Three-Step Test 6 (2004) (internal note omitted).

15. Mark J. Davison, Ann L. Monotti \& Leanne Wiseman, Australian Intellectual PROPERTY LAW 186 (2d ed. 2012).

16. SENFTLEBEN, supra note 14 , at 11 (internal note omitted).

17. See, e.g., DAVISON, Monotti \& Wiseman, supra note 15 at 188; SEnFtleben, supra note 14 , at 6 .

18. See generally Alfred C. Yen, Restoring the Natural Law: Copyright as Labor and Possession, 51 OHIO ST. L.J. 517-559 (1990); SENFTLEBEN, supra note 14, at 7-10. 
that reduction translates to greater sales. ${ }^{19}$ This approach is underpinned by the idea that "if users pirate less but the creators do not earn more, it is the culture that is losing." 20 This view has one foot each in the utilitarian and natural rights camps. Utilitarians see the grant of copyright as being necessary to encourage the creation and dissemination of knowledge and culture. This justification has long been favored in common law countries: the preamble of the Statute of Anne stated that it was "for the Encouragement of Learning, by Vesting the Copies of printed Books in the Authors, or Purchasers, of such Copies," ${ }^{21}$ and the United States Constitution gave Congress the power "To promote the Progress of Science and useful Arts, by securing for limited Times to Authors and Inventors the exclusive Right to their respective Writings and Discoveries." 22 A strictly utilitarian view would be interested in maximizing the creation and dissemination of content, and the extent to which those aims were achieved by infringement would only be relevant to whether that might deter future creation. By contrast, a strictly natural rights approach would focus on protecting the rights of authors regardless of whether doing so achieves any broader cultural ends.

Interestingly, though France's copyright law (the droit d'auteur) is strongly rooted in the natural rights tradition, the origins of its graduated response strategy show that the intention was not just to reduce infringement but to translate that into increased legitimate consumption. ${ }^{23}$ This may have been a pragmatic recognition of the fact that it is difficult to reduce infringement without offering reasonable legitimate alternatives: the Olivennes Report, on which the law was based, observed that "[i]t is difficult to deny the persistence of long delays is an invitation to piracy." 24 That dual aim was emphasized again in the Lescure Report, commissioned by the French Government to evaluate the success of the French law after several years of operation. ${ }^{25}$ Although major rights holders sometimes suggest that reduced infringement is a proper aim in and of itself, at other times they link reduced infringement to increased legitimate uptake. For example, the MPAA's response to the USPTO's call for submissions suggested that in the context of graduated response, "effectiveness" should be defined as a "decrease in consumer sharing of copyright infringing files; and . . . [an] increase in consumer accessing of legal digital content—ideally measured relative to a 'control' or what

19. See, e.g., Daniel Gervais, Copyright and eCommerce, in INTELLECTUAL ProperTY IN THE Global MarkeTPLACE (M. Simensky, L. Bryer and N.J. Wilkof eds., 2001).

20. Guillaume Champeau, Hadopi: le vrai bilan négatif de la riposte graduée, Numerama (May 9, 2013), http://www.numerama.com/magazine/25919-hadopi-le-vrai-bilan-negatif-de-la-ripostegraduee.html (quotation translated from the original French).

21. Statute of Anne, 1710, 8 Ann., c. 19, § 1 (Eng.).

22. U.S. Const. art. I, § 8, cl. 8.

23. Denis Olivennes, Le Developpement et la Protection des Oeuvres Culturelles sur les Nouveaux Reseaux, Ministere DE LA CUltURE ET DE LA COMMUNiCATION PT. 2 (2007), http://www. culture.gouv.fr/culture/actualites/conferen/albanel/rapportolivennes231107.pdf.

24. Id. at pt. 2.1.2 (via Google translate).

25. See infra Part II.A.1.a. 
they would have been in the absence of the initiative." 26 Accordingly, this work considers the extent to which graduated response regimes increase legitimate markets.

The third evaluation point is the extent to which graduated response laws encourage the creation and dissemination of a range of content. This is squarely rooted in the utilitarian idea that copyright is granted to promote broader public interest aims. As Samuelson and other members of the Copyright Principles Project (CPP) explain:

Copyright law should encourage and support the creation, dissemination, and enjoyment of works of authorship in order to promote the growth and exchange of knowledge and culture. .. . A successful copyright 'ecosystem' should nurture a diverse range of works. It should encourage creators to make and disseminate new works of authorship and support readers, listeners, viewers, and other users in experiencing those works. ${ }^{27}$

In its response to the USPTO's call for submissions, the Electronic Frontier Foundation (EFF) demonstrated similar priorities. It argued that "[i]]f the PTO evaluates private agreements meant to reduce copyright and trademark infringement, it should consider how well such agreements serve the ultimate goals of those statutes, which are not to 'reduce infringement' but to promote knowledge, grow the arts, and protect consumers." 28 Thus:

Effectiveness should be defined in terms of leading to the creation of more literature, audiovisual work, music, photography, software, etc., as well as creating a broader audience for those arts. This should be the primary measure of success of any copyright enforcement effort; indeed of any federal copyright policy. ${ }^{29}$

Although utilitarian considerations are far from being copyright law's only aim, they are the rhetorical linchpin of copyright policy in common law countries, and as Senftleben has persuasively demonstrated, have sometimes influenced civil law policy-making as well. ${ }^{30}$ Nothing else explains the fact that the European Copyright Directive records an intention for the harmonized framework to "foster substantial investment in creativity and innovation ... and lead in turn to growth and increased competitiveness of European industry." 31

26. Comments of the Motion Picture Ass'n of Am. in Response to Request of the USPTO. for Public Comments: Voluntary Best Practices Study 8 (Aug. 21, 2013), available at http://www.uspto. gov/ip/officechiefecon/PTO-C-2013-0036.pdf.

27. Pamela Samuelson, The Copyright Principles Project: Directions for Reform, 25 BERKELEY TECH. L.J. 1175, 1181 (2010).

28. Comments of the Electronic Frontier Found. in Response to Request of the USPTO for Public Comments: Voluntary Best Practices Study 1 (Aug. 21, 2013), available at http://www.uspto.gov/ip/ officechiefecon/PTO-C-2013-0036.pdf.

29. Id. at 2 .

30. SENFTLEBEN, supra note 14, at 10.

31. Council Directive 2001/29, On the Harmonisation of Certain Aspects of Copyright and Related Rights in the Information Society, 2001 O.J. (L 167/10) para. 4 (EC); SENFTLEBEN, supra note 14 , at 10 . 
If utilitarian considerations are relevant to the implementation of graduated response, then those schemes should be seeking to facilitate the creation of the greatest possible variety and widest distribution of cultural materials. This analysis will evaluate the extent to which they do so. If graduated response laws do not achieve these ends, it is harder to justify their continued adoption.

The following section will outline the mechanics of the various publicly and privately arranged graduated response schemes in existence around the world, providing a detailed and comprehensive snapshot of global graduated response law circa 2013. Readers who are already familiar with the way in which those laws operate may prefer to skip straight to the evaluative analysis in Part III, which considers the available evidence to determine the extent to which the various graduated responses are satisfying each of the above identified aims. The Article concludes by weighing the results of the analysis to determine whether the case has been made for retention or further adoption of graduated response.

\section{OUTLINE OF THE EXISTING SCHEMES}

\section{A. The Public Laws}

This section provides a detailed snapshot of the public graduated response laws operating in France, New Zealand, Taiwan and South Korea, as well as the current iteration of the still-evolving UK scheme. Organizations such as IFPI sometimes also claim Chile as a member of the graduated response club. ${ }^{32}$ However, Chilean law simply provides that, in order to enjoy the benefit of safe harbor provisions, service providers must have reserved the power to terminate subscriber accounts where a judge has declared the account holder to be a repeat infringer. ${ }^{33}$ This provision originates in the U.S. Digital Millennium Copyright Act, ${ }^{34}$ and Chile is just one of many countries to have imported it via a free trade agreement with the U.S. ${ }^{35}$ It does not impose any proactive obligations on ISP to police infringements and therefore will not be considered further in this Article.

32. See, e.g., Int'l Fed'n Phonographic Indus., IFPI Digital Music Report 2011, at 19 (2011), http://www.ifpi.org/content/library/DMR2011.pdf.

33. Law No. 20435, Abril 23, 2010, Diario Oficial [D.O.] (Chile) art. 85O, available at http://www.wipo.int/wipolex/en/text.jsp?file_id=241575.

34. See 17 U.S.C. § 512 (2010).

35. See Andrew Christie, Sophie Waller and Kimberlee Weatherall, Exporting the DMCA through Free Trade Agreements, in InTEllectual PROPERTY AND Free Trade AgReEMENTS (C. Heath and A.K. Sanders eds., 2007) (discussing importation of the D.M.C.A. via trade agreements). The text of the U.S.-Chile Free Trade Agreement is available at http://www.ustr.gov/sites/default/files/ uploads/agreements/fta/chile/asset_upload_file912_4011.pdf. 


\section{France}

\section{a. The Law}

The French graduated response law is known as HADOPI, an acronym for "Haute Autorité pour la diffusion des œuvres et la protection des droits sur internet" (or, in English, "High Authority for the Dissemination of Works and the Protection of Rights on the Internet"). ${ }^{36}$ The same term refers to both the law and the agency tasked with its administration. This Article will refer to the former as HADOPI, and the latter as Hadopi. ${ }^{37}$

The earliest iteration of the law, HADOPI-1, had envisaged an administrative body that would issue warnings to alleged infringers and have the power to suspend their Internet access up to twelve months if the behavior continued. ${ }^{38}$ This was overturned by the Constitutional Council, which held that only a judge, not an administrative body, had the power to suspend or terminate Internet access. ${ }^{39}$ In September 2009, a revised version-HADOPI-2 - allocated that power to a judicial authority instead, and this time largely survived the Council's scrutiny. ${ }^{40}$ HADOPI-2 came into operation in 2010. ${ }^{41}$ As discussed in more detail below, the law was significantly revised in July 2013. The following paragraphs describe how HADOPI-2 operated prior to July 2013, and then outline the changes made to create HADOPI-3.

Under HADOPI-2, accredited copyright owner representatives provided Hadopi with allegations of infringement. ${ }^{42}$ While the scheme was not expressly limited to infringement carried out via P2P file sharing technologies, rights holders initially focused their efforts on that variety of infringement. ${ }^{43}$ The Commission for

36. See HAUTE AUTORITE POUR LA DIFFUSION DES EUVRES ET LA PROTECTION DES DROITS SUR INTERNET, http://www.hadopi.fr (last visited Oct. 6, 2013).

37. A precursor to HADOPI, known as DADVSI, is discussed in Christophe Geiger, Honourable Attempt but (Ultimately) Disproportionately Offensive Against Peer-to-Peer on the Internet (HADOPI)_A Critical Analysis of the Recent Anti-File-Sharing Legislation in France, 42(4) INT'L REV. INTELL. PROP. \& COMPETITION L. 457, 458-465 (2011).

38. Rich Trenholm, France Passes Harsh Antipiracy Bill: Un, Deux, Trois You're Out, CNET (May 13, 2009), http://crave.cnet.co.uk/software/france-passes-harsh-antipiracy-bill-un-deux-troisyoure-out-49302255.

39. The judgment is available online at http://www.conseil-constitutionnel.fr/conseilconstitutionnel/root/bank/download/2009-580DC-2009_580dc.pdf. For a detailed discussion of the original legislation and the constitutional challenge, see Nicola Lucchi, Access to Network Services and Protection of Constitutional Rights: Recognizing the Essential Role of Internet Access for the Freedom of Expression, 19 CARDOZO J. INT'L AND COMP. L. 645, 650-672 (2007).

40. Alain Strowel, The 'Graduated Response' In France: Is it the Good Reply to Online Copyright Infringements?, in COPYRIGHT ENFORCEMENT AND THE INTERNET 148 (Irene A. Stamatoudi ed., 2010).

41. For a comprehensive description of the background to the Hadopi law's introduction, see Christophe Geiger, Counterfeiting and the Music Industry: Towards a Criminalization of End Users? The French "HADOPI" Example, in CRIMINAL ENFORCEMENT OF INTELlECTUAL PROPERTY: A HANDBOOK OF CONTEMPORARY RESEARCH 386 (Christophe Geiger ed., 2012).

42. Strowel, supra note 40 , at 149.

43. See, e.g., Johnny Ryan \& Caitriona Heinl, Internet Access Controls: Three Strikes 
Protection of Rights, "an autonomous body within the Hadopi in charge of the implementation of the graduated response," 44 then reviewed the allegations and, after verifying ownership, "identifie[d] the individuals concerned by requesting subscriber data from ISPs". ${ }^{45}$ The Commission could then decide to contact the user via their ISP, warning them that their Internet access should not be put to infringing use. ${ }^{46}$ The notice was required to alert the subscriber to the possible consequences of continuing infringement as well as information about legitimate offerings and the impact of infringement on copyright owners. ${ }^{47}$ If a second allegation was made within six months, the Commission could send another notice with the same information via email, together with a registered letter in the same terms. ${ }^{48}$ If any additional allegation was then made within a year of the second notification, the Commission would investigate the matter and prepare a report advising whether the subscriber's Internet connection should be suspended. ${ }^{49}$ The case file could then be forwarded to prosecutors, ${ }^{50}$ and then it would be up to a judge to determine what sanction, if any, should be imposed. ${ }^{51}$ Possible penalties included suspension of Internet access for up to twelve months ${ }^{52}$ and a fine of up to $1500 € .^{53}$ The law separately imposed liability on subscribers who were found to have negligently failed to secure their Internet connections (but who were not proved to have committed the resulting infringements themselves). ${ }^{54}$ The maximum fine was the same as for proven infringement, and the maximum suspension was a month instead of a year. ${ }^{55}$ Subscribers whose access was suspended under either mechanism were required to keep paying subscription fees during the term of any suspension, and they were not permitted to switch ISPs to avoid the sanction. ${ }^{56}$

Almost the entire cost of enforcing the law has been borne by the French Government and ISPs. The governmental contribution has been tens of millions of euros so far. ${ }^{57}$ It is unclear how much the scheme has cost ISPs. It has been

'Graduated Response' Initiatives, INST. OF INT’L AND EUR. AFF. 6 (2010), http://www.iiea.com/

documents/draft-overview-of-three-strikes-measures-nlm-study. This makes sense as P2P file sharing technologies permit identification of users' IP addresses and downloading activities in a way that is not generally feasible in the case of client-server direct download and streaming sites.

44. See Réponse graduée, HADOPI, http://www.hadopi.fr/usages-responsables/nouvelles-libertesnouvelles-responsabilites/reponse-graduee (last visited Nov. 10, 2013).

45. Strowel, supra note 40, at 149.

46. Id.; see also Réponse graduée, supra note 44.

47. Strowel, supra note 40, at 149-150.

48. Id. at 150-151.

49. Id.; Réponse graduée, supra note 44.

50. See Strowel, supra note 40, at 150-151.

51. Id.

52. $I d$.

53. Boris Manenti, The Repeal of HADOPI is Running, OBSESSION (Jul. 7, 2012), http://obsession.nouvelobs.com/high-tech/20120703.OBS5858/l-hadopi-court-toujours.html.

54. Code de la Propriété Intellectuelle [C. Prop. Intell.] art. R335-5 (Fr.).

55. Id.

56. Strowel, supra note 40 , at 151 .

57. Alexandre Laurent, Hadopi: $€ 12$ Million Budget for 2011, CluBIC (Sep. 30, 2010), 
suggested that the Hadopi agency has a legal obligation to cover ISPs' costs, but they have reportedly never been reimbursed. ${ }^{58}$ Rights holders have no obligation to contribute to the costs of administering the scheme or issuing notices, though they pay for and carry out the investigations on which infringement allegations are made..$^{59}$

Shortly after being elected, the Hollande government commissioned Pierre Lescure, former CEO of the Canal+ cable television network, to report on cultural policy, including the role and future of HADOPI. The Lescure Report, published in May 2013, found that HADOPI-2 had not achieved its aims. It concluded that, while it had perhaps brought about some reduction in P2P infringement, traffic had been diverted to other infringing sources rather than to the legitimate market. ${ }^{60}$ The report recommended abolishing the Hadopi agency, transferring its responsibilities elsewhere, reducing the maximum fine for infringement to $60 €$, and removing Internet termination as a possible remedy. ${ }^{61}$

The French government moved swiftly to respond to the report. On July 8 , 2013, it passed a decree introducing a regime that can be dubbed HADOPI-3. ${ }^{62}$ The decree abolished suspension as a possible penalty for a subscriber's failure to secure its connections, but retained the maximum fine of $1500 €{ }^{63}$ In an accompanying press release, the Culture Minister announced that the Hadopi agency would be abolished and its remaining responsibilities allocated elsewhere. ${ }^{64}$ The announcement explicitly explained that suspension was no longer seen as an appropriate remedy, and that the government would switch its enforcement focus to

http://pro.clubic.com/legislation-loi-internet/hadopi/actualite-369364-hadopi-12-budget-2011.html; Seamus Byrne, French Illegal Downloads Agency Hadopi May Be Abolished, CNET Australia (Aug. 6, 2012), http://m.cnet.com.au/french-illegal-downloads-agency-hadopi-may-be-abolished-339341011. htm.

58. French ISPs Demand Compensation for Hadopi Cooperation, TELECOMPAPER (Aug. 12, 2010), http://www.telecompaper.com/news/french-isps-demand-compensation-for-hadopi-cooperation; Battle of the Costs of Strikes New Zealander, TECHTEAM (2012), http://tech.techteam.gr/battle-of-thecosts-of-strikes-new-zealander/1324.

59. See New Zealand Federation Against Copyright Theft, Copyright (Infringing File Sharing) Regulations-Fee Review, MINISTRY FOR ECONOMIC DEVELOPMENT (2012), www.med.govt.nz/ business/intellectual-property/pdf-docs-library/copyright/notice-process/illegal-peer-to-peer-filesharing-submissions-on-fee-review-discussion/nzfact.pdf.

60. Pierre Lescure, Mission «Acte II de l'exception culturelle » Contribution aux politiques culturelles à l'ère numérique, MinisTERE DE LA CUlTURE ET DE LA COMMUNICATION (May 2013), www.culturecommunication.gouv.fr/var/culture/storage/culture_mag/rapport_lescure/index.htm\#/1, 371 .

61. Id. at 379-381.

62. Décret 2013-596 du 8 juillet 2013 supprimant la peine contraventionnelle complémentaire de suspension de l'accès à un service de communication [Decree 2013-596 of 8 July 2013 abolishing the additional penalty of suspending access to an online service of communication], JOURNAL OFFICIEL DE La REPUbliQue FrançAise [JO] [OFFICIAL GAZETTE OF FRANCE], Jul. 9 2013, p. 11428.

63. Id.

64. Publication du décret supprimant la peine complémentaire de la suspension d'accès à Internet, Ministere DE LA CUlture ET DE LA COMMUNiCATION (Jul. 9, 2013), www.culturecommunication.gouv.fr/content/download/72701/555642/file/130709_MCC\%20-

$\% 20$ cp $\% 20$ suspension $\% 20 \mathrm{~d} \% 27$ acc\% $3 \%$ A8s $\% 20 \%$ C $3 \%$ A0\%20internet.pdf. 
commercial piracy. ${ }^{65}$ Although suspension of Internet access remains a possible penalty in cases involving proven infringement (rather than failure to secure connections against infringement), it has been suggested that this penalty remains only because that provision could not be changed by simple decree. ${ }^{66}$

\section{b. Application So Far}

The first notices under HADOPI were sent in September 2010. ${ }^{67}$ By December, reports suggested that rights holders were issuing between 25,000 and 50,000 infringement allegations per day. ${ }^{68}$ By July 2011, the Commission had reportedly received 18,380,844 infringement allegations. ${ }^{69}$ However, as of the end of July 2013 (three years later), Hadopi had only issued 2,004,847 first notices and 201,288 second notices, and there have been just 710 "délibérations," or investigations, to see whether subscribers who have received three allegations should be referred to prosecutors (though it is not entirely clear whether this number covers current investigations, or only completed ones). ${ }^{70}$ That is, after almost three years of operation, the total number of allegations that had been acted upon reflected only $12 \%$ of the infringement allegations made in just the scheme's first eight months.

Of the users who do make it to the final stage, it appears that many are never actually referred for prosecution. An organization called "SOS Hadopi" has represented five individuals who reached the third strike stage, and the New York Times has reported that "all five [were] cleared before going to court."71 By the time the scheme had been operating for some twenty months, Hadopi had referred only fourteen cases to prosecutors for possible further action, ${ }^{72}$ and as of September

65. $I d$.

66. See, e.g., Bertrand Sautier, HADOPI to Disappear and the French Graduated Response System to be Partially Dropped, IPKAT (Jul. 10, 2013), http://ipkitten.blogspot.fr/2013/07/hadopi-todisappear-and-french.html; Marc Rees, Hadopi: la suspension est abrogée, l'échange avec les FAI est automatisé, PC INPACT (Jul. 9, 2013), www.pcinpact.com/news/81084-hadopi-suspension-est-abrogeeechange-avec-fai-est-fluidifie.htm

67. Int'l Fed'n Phonographic Indus., supra note 32, at 18.

68. Aymeric Pichevin, French Anti-Piracy Scheme's 25,000 Daily Reports, BILlBOARD (Oct. 22, 2010), http://www.billboard.biz/bbbiz/others/french-anti-piracy-scheme-s-25-000-daily-1004123926.

story (reporting 25,000 music related reports per day within a month of the regime commencing operation); Jared Moya, French 'Three-Strikes' Warnings Far Below Music Industry Hopes, ZEROPAID (Dec. 15, 2010), http://www.zeropaid.com/news/91562/french-three-strikes-warnings-far-below-musicindustry-hopes (reporting 50,000 submissions in December 2010).

69. Aymeric Pichevin, France's HADOPI Sends Out Final Copyright Infringement Notices, But Many Are Critical, BILLBOARD (Jul. 19, 2011), http://www.billboard.biz/bbbiz/others/france-s-hadopisends-out-final-copyright-1005282382.story.

70. Réponse graduée-Les chiffres clés, 1, 3, 5 HADOPI (Aug. 2013), http://www.hadopi.fr/sites/ default/files/page/pdf/Chiffresreponsegraduee_aout.pdf.

71. Eric Pfanner, Copyright Cheats Face the Music in France, N.Y. TIMES (Feb. 19, 2012), http://www.nytimes.com/2012/02/20/technology/20iht-piracy20.html.

72. Megan Geuss, French Anti-Piracy Agency Hadopi Only Sued 14 People in 20 Months, ARS TECHNICA (Sep. 5, 2012), http://arstechnica.com/tech-policy/2012/09/french-anti-piracy-agency-hadopionly-sued-14-people-in-20-months/?asid=03cabdde. 
2013, just four cases had gone to trial. In the first case, the Belfort Court fined a forty-year-old Frenchman $150 €$ after his IP address was associated with infringement of the song "Rude Boy" by Rihanna (represented by the Universal label). ${ }^{73}$ His then-wife had admitted using the connection to download songs. ${ }^{74}$ The penalty was imposed despite the account holder reportedly disconnecting his Internet access after the second warning, voluntarily attending the local police station, and paying to have his computer "cleaned." 75 In the second, a subscriber's IP address was associated with the infringement of French film "Heartbreaker."76 The Saint-Gaudens Court found him guilty of failing to secure his Internet connection, but decided not to impose any penalty on the basis that he did not fully understand the nature of the technology and the infringements alleged against him. ${ }^{77}$ In a third case, the subscriber was acquitted by the Lille Court for procedural irregularity; the notice had been dispatched too long after the alleged infringements took place. ${ }^{78}$ The judgment did not disclose the content the account holder was alleged to have infringed. ${ }^{79}$ In the fourth and final case to date, the subscriber was reportedly alleged to have infringed one song by Rohff (on the Warner Music Group label) and another by the Collectif Metissé (Universal). ${ }^{80}$ When the defendant did not appear in court, the District Court of Montreuil issued a default judgment imposing a fine of $600 €$ and requiring the relevant ISP to limit the subscriber's access for fifteen days. ${ }^{81}$ This was the first time the suspension power had ever been exercised. By contrast, the French culture minister had

73. The judgments applying HADOPI do not appear to be publicly available, but have been obtained and posted by a reporter for PC INPact. The judgment in the first can be found at Marc Rees, Hadopi: condamné pour un seul titre, flashé 150 fois, PC INPACT (Oct. 7, 2012), http://www.pcinpact. com/news/74364-hadopi-condamne-pour-seul-titre-flashe-150-fois.htm.

74. See id.

75. Cyrus Farivar, France Convicts First Person Under Anti-Piracy Law (Even Though He Didn't Do It), ARS TECHNICA (Sep. 13, 2012), http://arstechnica.com/tech-policy/2012/09/franceconvicts-first-person-under-anti-piracy-law-even-though-he-didnt-do-it.

76. See judgment posted at Marc Rees, Hadopi: condamné pour un seul film, flashé plus de 100 fois, PC INPACT (Feb. 19, 2013), http://www.pcinpact.com/news/77604-hadopi-condamne-pour-seulfilm-flashe-plus-100-fois.htm.

77. Id. This case is also discussed in Pierre Lescure, supra note 60.

78. See judgment posted at Marc Rees, Hadopi: le premier jugement de relaxe, PC INPACT (Jan. 23, 2013), http://www.pcinpact.com/news/76967-hadopi-premier-jugement-relaxe.htm; see also Julien L., Hadopi: la relaxe d'un suspect causée par une erreur de procedure, NuMERAMA (Jan. 11, 2013), www.numerama.com/magazine/24751-hadopi-la-relaxe-d-un-suspect-causee-par-une-erreur-deprocedure.html.

79. See judgment posted at Rees, supra note 78

80. Marc Rees, Première suspension Hadopi: un titre de Rohff, un autre du Collectif Métissé, PC INPACT (Jun. 17, 2013), http://www.pcinpact.com/news/80590-premiere-suspension-hadopi-titre-rohffautre-collectif-metisse.htm.

81. See judgment posted at Marc Rees, Hadopi: 15 jours de suspension contre un employé municipal, le jugement, PC INPACT (Jun. 20, 2013), http://www.pcinpact.com/news/80691-hadopi-15jours-suspension-contre-employe-municipal-jugement.htm. The circumstances of the case have been further reported at Marc Rees, Hadopi: $600 €$ d'amende et quinze jours de suspension pour un abonné, PC INPACT (Jun. 12, 2013), www.pcinpact.com/news/80487-hadopi-600-d-amende-et-quinze-jourssuspension-pour-abonne.htm. 
originally suggested that the scheme would result in 1000 disconnections per day. ${ }^{82}$

Notably, none of the four decided cases attempted to prove that the account holder actually engaged in the infringement. Instead, each involved the lesser charge of failing to appropriately secure an Internet connection, which, at the time, was punishable by a maximum fine of $1500 €$ and suspension for up to a month. ${ }^{83}$ As described above, the suspension penalty for that offence has now been abolished. It was announced that, due to the repeal, the one potential application of the penalty would not take place. ${ }^{84}$ At the time of writing, the future of the provision permitting suspension in cases of proven infringement by the subscriber is unclear. However, even if it remains on the books, its practical import is likely to be small: None of the cases decided to date have involved that charge, and even if a successful prosecution is brought in the future, courts may be disinclined to impose suspension in light of the government's message that it is an inappropriate penalty in cases of noncommercial infringement.

\section{New Zealand}

\section{a. The Law}

New Zealand was one of the earliest adopters of graduated response, making its first attempt to enact a statutory regime in $2008 .{ }^{85}$ Section $92 \mathrm{~A}$ of the 2008 Copyright (New Technologies) Amendment Act imposed an obligation on ISPs to "adopt and reasonably implement" policies for the termination of access to repeat infringers. Vigorously criticized for its breadth (its definition of "ISP" enveloped all organizations that provided Internet access, including libraries and schools) ${ }^{86}$ and for its lack of due process, the Government was forced to announce that the section would not come into force as scheduled, but would be "re-examined and reworked to address concerns." 87

Some three years later, the 2011 Copyright (Infringing File Sharing) Amendment Act repealed s92A and replaced it with a new framework. The new system came into effect for fixed line Internet access in September 2011; mobile

82. France, the First Country to Implement the Controversial 'Three-Strikes-and-You're-Out' Legislation, EPM MUSIC (Jun. 17, 2009), http://epm-music.com/digital-distribution/news/47-france-thefirst-country-to-implement-the-controversial-three-strikes-and-you-re-out-legislation.

83. Code de la Propriété Intellectuelle [C. Prop. Intell.] art. R335-5 (Fr.).

84. Marc Rees, Hadopi: la peine de 15 jours de suspension à Internet ne sera pas appliquée, PC INPACT (Sept. 5, 2013), http://www.pcinpact.com/news/82170-hadopi-peine-15-jours-suspension-ainternet-ne-sera-pas-appliquee.htm.

85. For a more detailed discussion of the N.Z. law, see Rebecca Giblin, On the (New) New Zealand Graduated Response Law (and Why It's Unlikely to Achieve Its Aims), 62(4) Telecomm. J. AUSTRALIA 54.1 (2012).

86. Internet Blackout NZ, CREATIVE FREEDOM NZ (2008), http://creativefreedom.org.nz/ blackout.html.

87. Government to Amend Section 92A: Press Release, New Zealand Government, ScooP INDEPENDENT NEWs (Mar. 23, 2009), http://www.scoop.co.nz/stories/PA0903/S00330.htm. 
providers will be obliged to follow suit from October 2015. ${ }^{88}$

The revised law is narrower in scope than its predecessors, and applies only to Internet Protocol Address Providers (IPAPs). ${ }^{89}$ This covers businesses that, other than as an incidental feature of their main commercial activities, transmit, route and provide connections for digital online communications, allocate IP addresses to their account holders, charge those account holders for their services, and do not primarily cater to transient users. ${ }^{90}$ The law is intended to capture only traditional ISPs, not organizations (like libraries and businesses) that merely provide incidental access to their members and employees. ${ }^{91}$

The law utilizes a three-notice framework. A rights holder can identify a subscriber as belonging to a particular IPAP via its IP address, and then contact it to make an infringement allegation. The IPAP must then identify the subscriber and issue an appropriate notice within seven days. ${ }^{92}$ Since the same IP address will typically be allocated to a vast number of subscribers over time, the IPAP must carefully identify the subscriber to which it was assigned at the time of the impugned conduct. A first notice relating to a particular subscriber from a right owner is referred to as a "detection notice," the second as a "warning notice" and the third as an "enforcement notice." In each case, the notice must include the name of the complainant rights holder, details concerning the infringement that triggered the notice, an explanation of the consequences, and instructions for challenging the notice should the recipient wish to do so. ${ }^{93}$

Applicant rights holders are required to defray the IPAP's costs of issuing notices. From the commencement of the scheme, regulations have capped that amount at NZ\$25 per notice. ${ }^{94}$ This allocation of costs has been controversial, with rights holders arguing that the per-notice fee is too high. A review carried out six months after the scheme came into operation found that, at that price point, ISPs were out of pocket between $\$ 5.50$ and $\$ 79$ each time they issued a notice. ${ }^{95}$ Nonetheless, the recording industry proposed that the fee be eliminated or reduced to $\$ 2$ or less, ${ }^{96}$ and the film industry—which, despite being a major driver of the

88. Section 2 of the Copyright (Infringing File Sharing) Amendment Act 2011 (N.Z.); section $122 \mathrm{~S}$ of the Copyright Act 1994, as amended by section 3 of the Copyright (Infringing File Sharing and Cellular Mobile Networks) Order 2013 (N.Z.).

89. Section 122A(1) of the Copyright Act 1994 (N.Z.).

90. Id.

91. Copyright (Infringing File Sharing) Amendment Bill 2010 No 119-1, Explanatory note, General policy statement, 4 (N.Z.). But see Pheh Hoon Lim and Louise Longdin, P2P Online File Sharing: Transnational Convergence and Divergence in Balancing Stakeholder Interests, 33(11) EUR. INTEL. PROP. REV. 690, 692 (2011) (suggesting that libraries and universities may nonetheless be captured by the scheme).

92. Section 122C(1) of the Copyright Act 1994 (N.Z.).

93. Id. at sections $122 \mathrm{D}(2), \mathrm{E}(2), \mathrm{F}(2)$.

94. Copyright (Infringing File Sharing) Regulations 2011, reg 7 (N.Z.).

95. Craig Foss, Copyright (Infringing File Sharing) Regulations-Review of Notice Fee, OFF. MINISTER OF COMM. 4 (2012), http://www.med.govt.nz/business/intellectual-property/pdf-docs-library/ copyright/notice-process/cabinet-paper.pdf.

96. Chris Caddick, Copyright (Infringing File Sharing) Regulations-Fee Review, RECORDING 
scheme, had refused to issue a single notice at the $\$ 25$ price point-argued that it should be eliminated altogether, or reduced to just a few cents. ${ }^{97}$ The review concluded that the fee should remain at $\$ 25$, since the claimed reduction in the amount of infringing file sharing suggested that cost considerations were not preventing the law from working as intended, and because at that rate ISPs were able to recover an appropriate amount of costs. ${ }^{98}$

To give subscribers an opportunity to take steps to prevent future infringements, there is no obligation to issue a notice if the allegation of infringement refers to conduct that occurred within twenty-eight days of an earlier one. ${ }^{99}$ Detection and warning notices each expire nine months after issue (or after the quarantine period, if an enforcement notice has been issued). ${ }^{100}$ Enforcement notices are valid for the quarantine period, which spans the thirty-five days from the issue of an enforcement notice. Once the notices expire, the cycle begins anew. The next allegation of infringement, if one occurs, will start the process again with a new detection notice. ${ }^{101}$

Unlike the French system, the rights holder need not provide evidence in support of an allegation of infringement. However, the subscriber may challenge any notice within fourteen days. ${ }^{102}$ If the rights owner does not reject the challenge within twenty-eight days, it is deemed to be accepted. ${ }^{103}$ If the challenge is rejected by the rights owner, the account holder has no further recourse at that time, but may raise its objections again during any subsequent enforcement proceedings. ${ }^{104}$

The requirement that the three notices issued to any given subscriber must relate to the same rights holder means that, theoretically, a subscriber could receive many more than three notices in the relevant period without any one rights holder being able to institute enforcement action. In practice, however, this requirement is considerably less difficult to satisfy than it first appears. That is because the Act effectively provides for rights owners to "pool" infringements. It does so by defining a "rights owner" as being either "a copyright owner" or "a person acting as agent for 1 or more copyright owners". ${ }^{105}$ It then provides that "[i]f a rights owner acts as agent for 1 or more copyright owners": (1) a reference to the copyright of a rights owner is to be taken as a reference to the copyright of any of the copyright owners for whom the rights owner acts as agent; and (2) a reference to infringement against a rights owner is to be taken as a reference to infringement against the

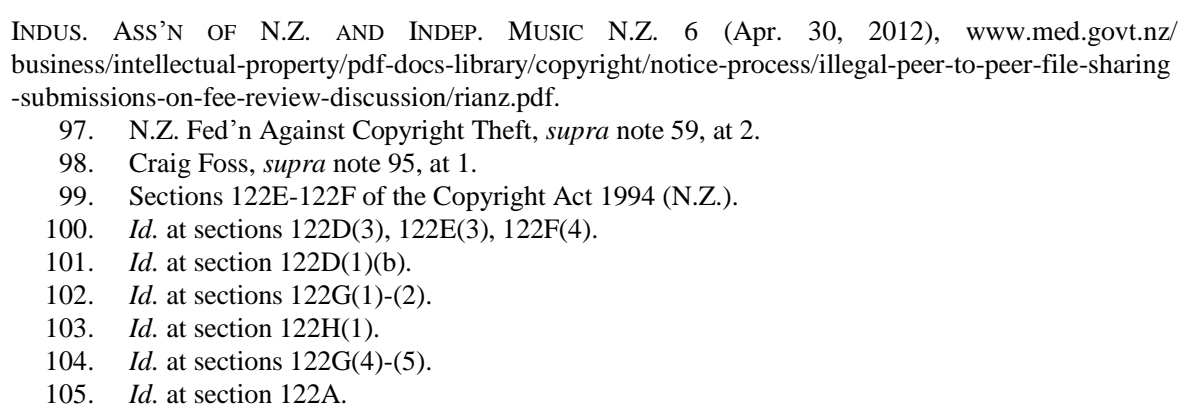


copyright of any of the copyright owners for whom the rights owner acts as agent. 106

After the "third strike," or enforcement notice, has finally been issued, the IPAP will provide a copy of it to the rights owner so they can seek redress. Although the New Zealand legislation does provide for repeat infringers to have their Internet access disconnected, those provisions are currently dormant and may only be brought into force by an Order in Council. ${ }^{107}$ Currently, the only available remedy is a financial penalty, which the infringing user may be ordered to pay by the Copyright Tribunal upon application from the rights holder. ${ }^{108}$ The Tribunal is required to order the penalty where it is satisfied that the allegations that triggered the infringement notices were committed from an IP address assigned to the account holder, and that the notices were validly issued-except where it considers it "manifestly unjust" to do so. 109

To calculate the sum payable, the Tribunal must add together the value of each infringed work, the amount paid by the rights owner to enforce its rights under the process and any amount the Tribunal "considers appropriate as a deterrent against further infringing." 110 In determining the latter, the Tribunal can take into account any relevant circumstances, including the flagrancy of the infringement and its possible effect on the market. ${ }^{111}$ The Regulations expressly anticipate that a sum may constitute a sufficient deterrent without the Tribunal imposing any additional impost. ${ }^{112}$ The Tribunal must then require an account holder to pay the identified sum, up to a ceiling of NZ\$15,000. ${ }^{113}$

\section{b. Application So Far}

Within the New Zealand scheme, the Recording Industry Association of New Zealand ("Rianz") appears to be the only rights holder to have issued any notices under the scheme. ${ }^{114}$ While comprehensive information regarding the number and source of notices is not publicly available, Rianz claims to have issued 2,766 notices between the commencement of the scheme in September 2011 and the end of April 2012. ${ }^{115}$ It has done so as agent for a number of record labels.

As of August 2013, the Tribunal had decided thirteen cases. It is worth briefly

106. Id. at section $122 \mathrm{~A}(2)$

107. Id. at section $122 \mathrm{R}(2)$.

108. Id. at section $122 \mathrm{O}$.

109. Id. at section $122 \mathrm{O}(1),(5)$.

110. Copyright (Infringing File Sharing) Regulations 2011, reg 12(2) (N.Z.).

111. Id. at reg $12(3)$.

112. Id. at reg 12(3)(c).

113. Section 122O(4) of the Copyright Act 1994 (N.Z.); Copyright (Infringing File Sharing) Regulations 2011, reg 12(1) (N.Z.).

114. See, e.g., Chris Keall, The Number of Infringement Notices Sent By the Movie Industry? None. Not a Sausage, NAT'L BuS. REv. (Jan. 31, 2013), http://www.nbr.co.nz/not-a-sausage (reporting that the National Business Review has been unable to discover any infringement notices issued by anyone other than Rianz by January 2013).

115. Caddick, supra note 96, at 1, 10 . 
considering the facts and resolutions reached in each, as they demonstrate some significant emerging patterns. In each case the applicant was Rianz, acting on behalf of various record labels. None of the cases involved three different infringements: instead, at least two of the notices always related to the same song. ${ }^{116}$ In each case, the Tribunal took the view that, because sending the first notices had an educative effect, the applicant should not be reimbursed for its full cost of issue, and that the reasonable cost of the copyrighted work should be determined by reference to the price at which that work could be purchased (without regard to the number of infringements the respondent may have facilitated). The sums awarded to deter further infringement represented the largest variable, and ranged from $\$ 0$ (in three cases where defendants responded and explained why they were unable or otherwise should not be obliged to pay) ${ }^{117}$ to $\$ 600$ ( $\$ 100$ for each of six detected infringements). ${ }^{118}$

\section{South Korea}

\section{a. The Law}

South Korea's graduated response scheme was enacted in April 2009.119 The Korean regime is unique in that it provides two separate pathways to termination of access. The first is based upon Article 133-2 of the Copyright Act 1959.120 Where infringing copies have been transmitted through "information and telecommunications networks," the Minister of Culture, Sports and Tourism ("the Minister") may order the online service provider to take a number of measures, including issuing warnings against the transmitters of illegal copies. ${ }^{121}$ Where an alleged infringer has received three or more warnings, the Minister may order suspension of the account. ${ }^{122}$ An associated Presidential Decree provides that a subscriber's first suspension must be for less than one month, the second for at least one but less than three months and the third for at least three but less than six months. ${ }^{123}$ While accounts are suspended, users are not prevented from signing up with other online service providers to resume access. ${ }^{124}$ Before the Minister can

116. The decisions are available at http://www.nzlii.org/nz/cases/NZCopyT/2013. (This paper reflects decisions decided up to and including September 1, 2013.)

117. See Recording Indus. Ass'n of N.Z. v CAL2012-E00609 [2013] NZCOP 5; Recording Indus. Ass'n N.Z. v Telecom N.Z. 4366 [2013] NZCOP 11; Recording Indus. Ass'n N.Z. v TCLE[A]-T6518151 [2013] NZCOP 12.

118. Recording Indus. Ass'n N.Z. v Telecom N.Z. 3728 [2013] NZCOP 8.

119. Jeremy de Beer and Christopher D. Clemmer, Global Trends in Online Copyright Enforcement: A Non-Neutral Role for Network Intermediaries?, 49 JURIMETRICS J. 375, 395 (2009).

120. Copyright Act, Act. No. 432, Jan. 28, 1957, amended by Act. No. 9625, Apr. 22, 2009, art.

133-2 (S. Kor.), translated in WIPO LEX, http://wipo.int/wipolex/en.

121. Id.

122. Id.

123. Enforcement Decree of the Copyright Act, Presidential Decree No. 22003, Jan. 27, 2010, art. 72-3(3) (S. Kor.), translated in WIPO LEX, http://wipo.int/wipolex/en.

124. Sun-Young Moon and Daeup Kim, The 'Three Strikes' Policy in Korean Copyright Act 2009: 
issue the order, the matter will be deliberated by the Korea Copyright Commission. ${ }^{125}$ The regulations provide that the Commission must take into account factors such as the alleged infringer's recidivism, the volume of copies reproduced and/or transmitted, the type of copies and possibility of market substitution, and the impact of the unlawful copies on legitimate distribution. ${ }^{126}$

The second pathway to disconnection from Internet services is via recommendation of the Commission itself. It has authority to make various recommendations to online service providers, including that they issue warnings to infringers, delete infringing copies or suspend accounts which have been repeatedly involved in infringement. ${ }^{127}$ Unlike the Article 133-2 procedure, the Act does not require any prior warnings - only a determination that infringement is "repeated." As IP activist Heesob Nam explains:

In this regard, the suspension by the Commission's recommendation is neither a threestrike rule nor a notice-suspension system. The Korean government also does not call this a three-strike rule. But the reason is quite different. It is not a three-strike rule because the suspension is a voluntary measure taken by an ISP $\ldots .{ }^{128}$

While the Commission is not required to give warnings prior to disconnection, Nam reports that it has an internal bylaw which does mandate multiple warnings before it recommends disconnection. ${ }^{129}$

It is important to emphasize that suspension is not limited to Internet access, but also covers user accounts on various services. The Commission bears all costs associated with the scheme, other than the costs of investigations carried out by rights holders. ${ }^{130}$

\section{b. Application So Far}

Between the South Korean scheme's commencement in July 2009 and the end of 2012, 468,446 warnings and takedown notices were issued. ${ }^{131}$ This figure includes the suspensions imposed by the Commission as well as the Minister, though in 2012 the Minister issued no warnings and required no suspensions. ${ }^{132}$

Safe or Out?, 6 WASH. J. L., TECH. \& ARTS 171, 175-176 (2011).

125. Copyright Act, Act. No. 432, Jan. 28, 1957, amended by Act. No. 9625, Apr. 22, 2009, art. 133-2 (S. Kor.), translated in WIPO LEX, http://wipo.int/wipolex/en.

126. Enforcement Decree of the Copyright Act, Presidential Decree No. 22003, Jan. 27, 2010, art. 72-3(3)(1) (S. Kor.), translated in WIPO LEX, http://wipo.int/wipolex/en.

127. Copyright Act, Act. No. 432, Jan. 28, 1957, amended by Act. No. 9625, Apr. 22, 2009, art. 133-3 (S. Kor.), translated in WIPO LEX, http://wipo.int/wipolex/en.

128. Heesob Nam, Facts and Figures on Copyright Three-Strike Rule in Korea, HEESOB's IP BLOG (Oct. 24, 2010, 3:20 PM), http://hurips.blogspot.com.au/2010/10/facts-and-figures-on-copyrightthree.html.

129. Id.

130. N.Z. Fed'n Against Copyright Theft, supra note 59, at 2-3.

131. Copyright Reform-Abolishing Three-Strikes-Out Rule from Copyright Law, OPENNET http://reformcopyright.opennet.or.kr (last visited Nov. 20, 2013).

132. Id. 
Although ISPs are required to act on the Minister's orders, they have discretion regarding whether they act on the Commission's recommendations. ${ }^{133}$ In practice, however, they consistently do so. Data for the first year the scheme was in operation demonstrates that ISPs suspended user accounts in response to $99.94 \%$ of Commission recommendations. ${ }^{134}$ None of the suspensions under either the Commission or Ministerial processes were of Internet access — only for accounts to other services, such as online file hosting. ${ }^{135}$ To provide some context to these numbers, South Korea had over forty million Internet users in 2011. ${ }^{136}$

In March 2013, the National Human Rights Commission of South Korea called for the three strikes law to be repealed. ${ }^{137}$ The Commission reportedly questioned the law's regulatory effectiveness, and found that it "may restrict the right to culture and information." 138 Around the same time, a dozen members of the Korean National Assembly introduced a Bill seeking to repeal the law. ${ }^{139}$ As in France, the law's future is far from assured.

\section{Taiwan}

\section{a. The Law}

Taiwan was another early adopter of graduated response. However, Taiwan's version seems to have fewer teeth than that of its northern neighbor. Its Internet Service Provider (ISP) Liability Limitation Bill was passed on April 21, 2009 and amended the principal Copyright Act. ${ }^{140}$ The scheme links a three strikes system together with immunity for complying ISPs. Article 90quinquies provides that ISPs will only be entitled to rely on statutory safe harbors where they: (1) inform users of their copyright or plate right protection policies and take "concrete action"

133. Doug Jay Lee, Misung Kim \& Jong Won Hong, Korea APAA Copyright Committee, ANNUAL REPORT 2009 at 7 (2009), available at $\mathrm{http} / / / \mathrm{www}$.apaaonline.org/pdf/APAA_56th_\&_57th_ council_meeting/copyright/2-Korea\%20Copyright\%20Cttee\%20Country\%20Report\%202009.pdf.

134. Heesob Nam, Facts and Figures on Copyright Three-Strike Rule in Korea, HEESOB's IP BLOG (Oct. 24, 2010), http://hurips.blogspot.com.au/2010/10/facts-and-figures-on-copyright-three.html.

135. Id.

136. South Korea-New Media Trend Watch Long-Haul, New MEDIA TREND WATCH, www.newmediatrendwatch.com/markets-by-country/11-long-haul/63-south-korea (last updated Jun. 29, 2013).

137. At time of writing, there is no English-language translation of the report available. The report is available in Korean at www.humanrights.go.kr/common/board/fildn_new.jsp?fn=1364343699994.pdf. An English-language description of the report's findings is available at Heesob Nam, National Human Rights Body Recommends Abolishing Three-Strike-Out Rule, HeEsOB's IP BlOG (Mar. 27, 2013), http://hurips.blogspot.kr/2013/03/national-human-rights-body-recommends.html.

138. Nam, supra note 137.

139. Jae Yeon Kim, South Korean Politician Moves to Repeal Biased Copyright Law, GloBAL VoiceS ADVOCACY (Mar. 28, 2013), http://advocacy.globalvoicesonline.org/2013/03/28/south-koreanpolitician-moves-to-repeal-biased-copyright-law.

140. Yulan Kuo \& Charles Chen, Taiwan Provides Safe Harbour for ISPs in Copyright Infringement Cases-International Report, INTEL. AsseT MGMT. (July 22, 2009), http://www.iammagazine.com/reports/detail.aspx?g=8e991417-0853-4730-9bb6-3c45ebbf8f97. 
to implement them; (2) inform users that in the event of repeat alleged infringements (up to three times) the service provider shall terminate the service in whole or in part; (3) publicly announce information regarding their "contact window" for receipt of notification documents; and (4) pass on notifications alleging infringement to the relevant user, and implement technical measures for protecting copyrighted or plate-righted works, if those measures have been ratified by the "competent authority." 141

It is notable that the law does not actually require ISPs to terminate user access, but only to advise users that they will do so. ${ }^{142}$ The accompanying regulations provide little detail about how the scheme is to operate in practice. They simply set out the contact information that ISPs must make available, ${ }^{143}$ the particulars that must be contained in any notification or counter-notification regarding an infringement allegation, ${ }^{144}$ and the circumstances in which ISPs may require issuers to correct inadequate notifications or counter-notifications. ${ }^{145}$

One possible explanation for the scheme's lack of detail can be gleaned from commentary published by a Taiwanese law firm in late 2009. It suggested that "[t]he amendments to the Copyright Act and the regulations appear to have been carefully thought through to appease those parties lobbying for the inclusion of a 'three-strikes' mechanism while ensuring that the ISP and individual users of connection services have a degree of protection." 146

\section{b. Application So Far}

Although the Taiwanese scheme has now been in operation for several years, there are no reports of any user actually having his or her access suspended under the law. Despite the scheme's limitations, IFPI has cited Taiwan approvingly when reporting its successes on the graduated response front, ${ }^{147}$ and the country's efforts towards implementing graduated response were cited as a key reason for Taiwan's removal from the USTR's "special watch list" in 2009. ${ }^{148}$

141. Copyright Act, art. 90quinquies (2007) (Taiwan).

142. See, e.g., Johnny Ryan \& Catriona Heinl, Internet Access Controls: Three Strikes 'Graduated Response' Initiatives 16 (May 2010) (note for comment) (on file with the Institute of International and European Affairs), available at http://www.iiea.com/documents/draft-overview-of-three-strikesmeasures-nlm-study.

143. Regulations Governing Implementation of ISP Civil Liability Exemption, art. 2 (2009) (Taiwan).

144. Id. at arts. 3,5 .

145. Id. at arts, 4,6 .

146. See WinkLER PARTNERS, Implementing Regulations For ISP Safe Harbor Amendments Announced, WAYBACK MACHINE, http://web.archive.org/web/20100302092545/http://www. winklerpartners.com/a/2009/11. The relevant regulations are available at Regulations Governing Implementation of ISP Civil Liability Exemption, INTELL. PROP. OFF., available at www.tipo.gov.tw/ (downloadable regulations listed in "Laws and Regulations," available by visiting the main site, selecting "English," and selecting "Copyright").

147. See, e.g., John Kennedy, IFPI Digital Music Report 20103 (2010), available at www.ifpi.org/content/library/DMR2010.pdf.

148. Off. U.S. Trade Rep., USTR Announces Conclusion of the Special 301 Out-Of-Cycle Review 


\section{United Kingdom}

\section{a. The Law}

The final public law graduated response regime is that of the UK. Given that the regime has yet to come into operation, its effects cannot be evaluated. However, the design of the UK model and the hurdles faced by those seeking to implement it are nonetheless instructive.

The framework for the UK's graduated response is contained in the Digital Economy Act 2010 (U.K.), which amended the Communications Act 2003 (U.K.). ${ }^{149}$ The statute was designed to be supplemented by two pieces of secondary legislation: a so-called "Initial Obligations Code," which would contain the details of the way in which the notification scheme would operate, ${ }^{150}$ and a "Costs Order," which would determine the allocation of the scheme's costs. ${ }^{151}$ Communications industry regulator Ofcom is charged with formulating both documents. Ofcom published a draft version of the Initial Obligations Code in May 2010, ${ }^{152}$ and it laid an initial draft of the Costs Order before Parliament in early 2011. ${ }^{153}$ Two ISPs sought judicial review to clarify the compatibility of the Digital Economy Act and draft Costs Order with various EU directives. ${ }^{154}$ Their challenge resulted in the exemption of ISPs from any obligation to contribute to the costs of Ofcom or the appeals body in carrying out their functions, or to the costs of appeals, but it was otherwise rejected. ${ }^{155}$ Ofcom released modified versions of the draft Initial Obligations Code and Costs Order in June 2012,156 expecting the statutory instruments to be reviewed by the EC and put before the UK Parliament by the end of 2012. ${ }^{157}$ However, as of June 2013, more than three years after the Digital

for Taiwan (Jan. 2009), www.ustr.gov/about-us/press-office/press-releases/2009/january/ustr-announces -conclusion-special-301-out-cycle-re.

149. Communications Act, 2003, c. 21 (U.K.), available at http://www.legislation.gov.uk/ukpga/ 2003/21/pdfs/ukpga_20030021_en.pdf. See Also Digital Economy Act, 2010, c. 24 (U.K.).

150. Digital Economy Act, 2010, c. 24, §§ 124D, 124E (U.K.) (amending Communications Act, 2003, c. 21 (U.K.)); see also Off. Comm., Online Infringement of Copyright: Implementation of the Online Infringement of Copyright (Initial Obligations) (Sharing of Costs) Order 2012, OfCOM (June 2012), http://stakeholders.ofcom.org.uk/consultations/infringement-implementation/summary.

151. Digital Economy Act, 2010, c. 24, § 124M (U.K.) (amending Communications Act, 2003, c. 21 (U.K.)); see also Off. Comm., supra note 150.

152. See Off. Comm., Online Infringement of Copyright and the Digital Economy Act 2010, OFCOM, (May 2010), http://stakeholders.ofcom.org.uk/consultations/copyright-infringement.

153. See Draft Statutory Instrument-the Online Infringement of Copyright (Initial Obligations) (Sharing of Costs) Order 2011, Gov.UK (2011), https://www.gov.uk/government/uploads/system/ uploads/attachment_data/file/78348/10-1199-Darft-SI-online-infringement-of-copyright-costs-order.pdf.

154. British Telecomm. Plc v. Sec'y of State for Culture, Olympics, Media and Sport, [2012] EWCA Civ. 232, [1] (appeal taken from Eng.).

155. See id. at [101-107].

156. Off. Comm., Notice of Ofcom's Proposal to Make by Order a Code for Regulating the Initial Obligations, OFCOM (June 26, 2012), http://stakeholders.ofcom.org.uk/binaries/consultations/onlinenotice/summary/notice.pdf; Off. Comm., supra note 150.

157. Off. Comm., New Measures to Protect Online Copyright and Inform Consumers, OFCOM (June 26, 2012), http://media.ofcom.org.uk/2012/06/26/new-measures-to-protect-online-copyright-and- 
Economy Act received Royal Assent, ${ }^{158}$ neither hurdle has been overcome. This is largely attributable to continued controversies regarding the allocation of costs. In July 2012, the House of Lords Secondary Legislation Scrutiny Committee drew the revised Costs Order "to the special attention of the House on the grounds that it gives rise to issues of public policy likely to be of interest to the House and it may imperfectly achieve its policy objective." 159 The Committee was particularly concerned about the allocation of costs being decided before key aspects of the scheme were finalized (and thus while the actual costs remained unknown). ${ }^{160}$ More recently, it has also been suggested that the continued delays in laying the revised Costs Order before Parliament are due to a dispute regarding whether Treasury approval is also necessary. ${ }^{161}$

The UK scheme envisages a two-tiered response to allegations of repeat infringement. It draws a distinction between "initial obligations" (which will apply from the time the scheme is finally implemented) and "technical obligations" (which will not apply until some time later, if at all). Strictly speaking, the scheme utilizes a "notice and notice" framework, rather than a "notice and sanction" one, as the initial obligations do not impose any penalties on repeat infringers. However, the scheme does make it easier for rights holders to identify repeat infringers, and it places obligations on ISPs to assist in the policing of their users; this makes it appropriate to include the UK in the graduated response club.

At this stage, it is by no means clear that either statutory instrument will ever be passed. However, the following analysis provides an overview of how the scheme will work if it is implemented as currently drafted.

If and when the scheme finally comes into operation, ISPs will have two "initial obligations." The first requires them to notify subscribers of allegations of infringement made by rights holders, in accordance with detailed procedures set out within the Act and the Initial Obligations Code. The second obligation is to maintain infringement lists in accordance with that Code, which must be provided to rights holders upon request. ${ }^{162}$ The lists will be required to identify, on an anonymous basis, all subscribers who have at least the threshold number of infringement reports in relation to the requesting copyright owner. ${ }^{163}$ Rights holders could then seek disclosure of the personal information of subscribers via

inform-consumers/.

158. British Telecomm. Plc. v. Sec'y of State for Culture, Olympics, Media and Sport, [2012] EWCA Civ. 232, [21] (appeal taken from Eng.).

159. Secondary Legis. Scrutiny Comm. Seventh Report: Instruments Drawn to the SPecial AtTENTION OF THE House, 2012-3, para. 17 (U.K.), available at http://www.publications. parliament.uk/pa/ld201213/ldselect/ldsecleg/32/3203.htm.

160. Id. para. 37.

161. James Firth, Sources: No Digital Economy Act Copyright Warning Letters Until 2016 at the Earliest, SLIGHTLY Right OF CENTRE (May 30, 2013), http://www.sroc.eu/2013/05/sources-no-digitaleconomy-act.html?m=1.

162. Digital Economy Act, 2010, c. 24, § 124B (U.K.) (amending Communications Act, 2003, c. 21 (U.K.)).

163. Id. $\S 124 \mathrm{~B}(2)-(3)$. 
court order.

The draft Initial Obligations Code provides that the scheme will only apply to the largest ISPs - those who offer 400,000 or more broadband-enabled lines. ${ }^{164}$ Ofcom justifies this on the basis that, for others, "costs of participation would be disproportionately high compared to the expected low reduction in overall levels of online copyright infringement that participation would bring." 165 The scheme will also be limited to certain pre-defined rights holders. The Code applies only to "qualifying copyright owners," defined as copyright owners who have "made an estimate of the number of copyright infringement reports [they] will make to a qualifying [I]nternet service provider in that notification period" and who have provided that estimate to ISPs and Ofcom. ${ }^{166}$ Special arrangements will apply to the first notification period, but estimates of notice levels must be provided at least two months before the beginning of subsequent notification periods. ${ }^{167}$ ISPs will have no obligation to issue notices unless and until the copyright owner has paid the issuance fee in full. ${ }^{168}$

Ofcom must approve the evidence gathering and verification procedures of qualifying copyright owners before they can begin issuing notices to ISPs. ${ }^{169}$ The UK scheme is not restricted to infringements committed via P2P file sharing technologies. However, as the gathering of evidence concerning widespread infringement tends to focus on P2P networks, it is likely that this technology will nonetheless trigger the bulk of allegations.

After the first copyright infringement report for any given user is sent to an ISP by a rights holder, the ISP must match the IP address and send an "initial notification" to the associated subscriber. ${ }^{170}$ On the second occasion, an "intermediate notification" must be sent alerting the subscriber to the allegation and warning him that a third notification may result in his inclusion on a copyright infringement list. ${ }^{171}$ If a third copyright infringement report is made against the same subscriber within the twelve-month period, the ISP must notify the account holder of the allegation and explain that, upon request, a statement setting out the infringement reports made by a particular copyright owner in relation to them may be provided to that copyright owner. ${ }^{172}$ The notice must explain that, while the subscriber's identity will not be disclosed, the rights holder may seek a court order for disclosure and may bring legal action against the subscriber for infringement. ${ }^{173}$

164. Off. Comm., Notice of Ofcom's Proposal to Make by Order a Code for Regulating the Initial Obligations, OFCOM 3 (June 26, 2012), http://stakeholders.ofcom.org.uk/binaries/consultations/onlinenotice/summary/notice.pdf.

165. Id.

166. Id. at 18 .

167. Id.

168. Id. at 4 .

169. Id. Annex 3 (Draft Initial Obligations Code), $\$ 6$.

170. Id. Annex 3 (Draft Initial Obligations Code), § 11.

171. Id. Annex 3 (Draft Initial Obligations Code), § 12.

172. Id. Annex 3 (Draft Initial Obligations Code), § 13.

173. Id. 
Fourth and subsequent notifications must be issued in a similar ways. ${ }^{174}$ Rights holders are permitted to seek a list of subscribers who have reached the "three strike" threshold from each ISP up to once a month, and ISPs must comply within ten working days. ${ }^{175}$ The lists will contain only the allegation(s) of infringement referable to the requesting rights holder. ${ }^{176}$ Copyright infringement reports will remain active for twelve months after receipt by the ISP. ${ }^{177}$

Rights holders must send their infringement allegations to ISPs within a month of the supporting evidence being gathered, ${ }^{178}$ and ISPs have a further month to notify subscribers of the allegation. ${ }^{179}$ To give putative infringers an opportunity to remedy their ways (or secure their networks), there must be a minimum twenty-day grace period between any previous notification and the evidence which triggers the next. ${ }^{180}$

Subscribers will be able to appeal notifications alleging infringement to a designated body, ${ }^{181}$ but must do so within twenty working days of receiving the notice or infringement report. ${ }^{182}$ There are four possible grounds for appeal: (1) that the apparent infringement to which a copyright infringement report relates was not actually an infringement; (2) that the copyright infringement report did not relate to the subscriber's IP address at the relevant time; (3) that the act constituting the apparent infringement was not done by the subscriber (and the subscriber took reasonable steps to prevent other persons infringing copyright by means of the Internet access service); and (4) that there was a contravention of the Initial Obligations Code or related regulation by a participating copyright owner or ISP. ${ }^{183}$

The appeals body must find in favor of the subscriber unless the copyright owner shows that the alleged infringement was in fact infringing, and unless the relevant ISP shows that the IP address set out in the infringement report was indeed allocated to the subscriber at the relevant time. ${ }^{184}$ Appeals must also be determined in favor of the subscriber where the subscriber demonstrates that she did not commit the act constituting the apparent infringement, and that she took reasonable steps to prevent others from infringing via her account. ${ }^{185}$

As noted above, the allocation of the costs of the scheme has generated considerable controversy. Ofcom's current draft consultation paper on the sharing of costs proposes that: (1) copyright owners will bear the costs incurred by Ofcom

174. Id. Annex 3 (Draft Initial Obligations Code), § 14.

175. Id. Annex 3 (Draft Initial Obligations Code), § 19.

176. Id.

177. Id. Annex 3 (Draft Initial Obligations Code), § 10.

178. Id. Annex 3 (Draft Initial Obligations Code), § 4.

179. Id. Annex 3 (Draft Initial Obligations Code), § 15.

180. Id. Annex 3 (Draft Initial Obligations Code), §§ 12, 13. For fourth and subsequent "strikes," there must be at least a ninety day grace period. See id. Annex 3 (Draft Initial Obligations Code), $\S 14$.

181. Id. Annex 3 (Draft Initial Obligations Code), § 24.

182. Id. Annex 3 (Draft Initial Obligations Code), § 26.

183. Id. Annex 3 (Draft Initial Obligations Code), $\$ 25$.

184. Id. Annex 3 (Draft Initial Obligations Code), § 29.

185. Id. 
in setting up the system (with each owner's contribution being proportionate to the number of notices it proposes to send); ${ }^{186}$ (2) copyright owners will bear the costs of processing any appeal against an allegation they have made (other than $£ 20$ that each appellant must contribute, and which will be refunded if the appeal is upheld); ${ }^{187}$ and (3) copyright owners will bear $75 \%$ of the costs "efficiently and reasonably incurred by ... ISPs in carrying out their obligations," with this again being determined pro rata with reference to the number of notices each owner proposes to send. Participating ISPs will contribute the remaining 25\%. ${ }^{188}$

Copyright owners have indicated an intention to issue some two million copyright infringement reports each year, but made it clear that "their cooperation is entirely dependent on financial considerations." 189 The Impact Assessment of the current version of the Costs Order estimates Ofcom's likely set-up costs at $£ 5.8$ million, and the capital costs of ISPs at a further $£ 7.6$ million ${ }^{190}$ (although ISPs have argued that the proposed Costs Order significantly underestimates their likely costs). ${ }^{191}$ The Secondary Legislation Scrutiny Committee has expressed concern that rights holders have no obligation to actually use the system if and when it is implemented. ${ }^{192}$ If they choose not to, or if volumes are significantly lower than expected, these hefty start-up costs may not be recoverable.

\section{b. Application So Far}

ISPs will have no obligations under the law until the Initial Obligations Code comes into effect. ${ }^{193}$ It is not clear when (or if) this will occur. It was originally anticipated that the first notices would be issued by the beginning of $2011,{ }^{194}$ but Ofcom has most recently indicated that the first notifications are expected to be sent three years late, "in early 2014."195 This deadline looks impossible to meet,

\footnotetext{
186. Off. Comm., supra note 150 , at 1.

187. Id.

188. Id.

189. SECONDARY LEGIS. SCRUTINY COMM., supra note 159,

190. DePt. Culture, Media \& SPORT, IMPaCt Assessment of DRAFt SI "The Online INFRINGEMENT OF COPYRIGHT (INITIAL OBLIGATIONS) (SHARING OF COSTS) ORDER 2011," 2011, at 9, 10 (U.K.), https://www.gov.uk/government/uploads/system/uploads/attachment_data/file/78093/IA_ Sharing_of_Costs_Sl.pdf.

191. See, e.g., Ofcom Sharing of Costs Order Consultation (June 2012)-BT Response, BT (Sep. 21, 2012), http://stakeholders.ofcom.org.uk/binaries/consultations/onlinecopyright/responses/BT.pdf; Everything Everywhere's Response to Ofcom's Online Infringement of Copyright: Implementation of the Online Infringement of Copyright (Initial Obligations) (Sharing of Costs) Order 2012, EvERYTHING EVERYWHERE (Sep. 18, 2012), http://stakeholders.ofcom.org.uk/binaries/consultations/onlinecopyright/ responses/Everything_Everywhere.pdf; TalkTalk Group Submission, TALKTALK (Sep. 2012), http://stakeholders.ofcom.org.uk/binaries/consultations/onlinecopyright/responses/TalkTalk_Group.pdf.

192. SECONDARY LEGIS. SCRUTINY COMM., supra note 159, I[ 26.

193. See Off. Comm., supra note 150, at 23.

194. See, e.g., Emma Barnett, Digital Economy Act: What Happens Next?, ThE TelegraPH (Apr. 9, 2010), http://www.telegraph.co.uk/technology/news/7571532/Digital-Economy-Act-what-happensnext.html.

195. Online Infringement of Copyright and the Digital Economy Act 2010, 2011, supra note 152, at 7.
} 
given that the statutory instruments have not yet been passed. Music Week has reported that implementation may now not occur until "late 2014 or even 2015 ". ${ }^{196}$ Digital policy expert James Firth has cited Westminster sources suggesting that the statutory instruments won't be passed before the general election (expected in 2015), and hypothesized that the first warning notices won't be dispatched before 2016. 197

The scheme is intended to bring about a $75 \%$ reduction in infringement committed by UK Internet users. ${ }^{198}$ In the event that it is insufficiently effective, the Secretary of State may choose to impose the second-tier measures, which are referred to as "technical obligations." These may include "bandwidth capping or shaping that would make it difficult for subscribers to continue file-sharing. . . If appropriate, temporary suspension of broadband connections could be considered."199 Permanent disconnection will not be an option. Technical obligations cannot be imposed until at least twelve months after the initial obligations have been in operation, ${ }^{200}$ and Ofcom must first make "a technical obligations code for the purpose of regulating those obligations." 201 Given how long it has taken to get to this stage of the initial obligations phase - and how far away it still seems from implementation-technical obligations may not be introduced for many years, if at all. In recognition of this reality, it was reported in September 2013 that the British Video Association and British Recorded Music Industry groups have started pushing for ISPs to separately adopt voluntary measures to police infringement. ${ }^{202}$

\section{B. The Private Arrangements}

In addition to the public laws described above, private agreements are in place between various rights holders and ISPs around the world. This section provides an overview of the most notable of these, which operate in Ireland and the United States. ${ }^{203}$

196. Tim Ingham, Digital Economy Act Delayed AGAIN, MUSICWEEK (Feb. 7, 2013), http://www. musicweek.com/news/read/digital-economy-act-delayed-again/053507.

197. James Firth, Sources: No Digital Economy Act Copyright Warning Letters until 2016 at the Earliest, SLIGHTLY Right OF CENTRE (May 30, 2013), http://www.sroc.eu/2013/05/sources-no-digitaleconomy-act.html?m=1.

198. SECONDARY LEGIS. SCRUTINY COMM., supra note 159.

199. See, e.g., Johnny Ryan \& Catriona Heinl, Internet Access Controls: Three Strikes 'Graduated Response' Initiatives, 13 (2010), available at http://www.iiea.com/documents/draft-overview-of-threestrikes-measures-nlm-study (citing Explanatory Notes, Digital Economy Act, 2010, c. 24 (U.K.)).

200. Communications Act, 2003, c. 21, § 124, amended by Digital Economy Act, 2010, c. 24, § $124 \mathrm{H}$ (U.K.).

201. Id. § $124 \mathrm{I}$.

202. Juliette Garside, Record Labels Ask Broadband Providers to Collect Data on Illegal Downloads, THE GuARDIAN (Sept. 1, 2013), http://www.theguardian.com/technology/2013/sep/01/ record-labels-broadband-database-illegal-downloads.

203. For more detailed discussion of these schemes, and the rationales for the shift away from enforcement via litigation and towards private ordering, see Annemarie Bridy, Graduated Response and the Turn to Private Ordering in Online Copyright Enforcement, 89 OR. L. REv. 81 (2010); Annemarie 


\section{Ireland}

\section{a. The Law}

The Irish scheme is the most closely analogous to the Australian experience, having emerged from litigation between various record industry companies and Eircom, Ireland's largest ISP. The record companies sought to force the installation of filtering technologies to block infringing downloads at the ISP level. ${ }^{204}$ However, after eight days of evidence, and before the Court ruled on the matter, the parties reached a settlement involving the implementation of a private "three strikes" scheme. ${ }^{205}$

The precise terms of the graduated response protocol negotiated via the settlement are confidential. ${ }^{206}$ However, its main contours can be pieced together from a decision of the High Court of Ireland considering whether the settlement complied with relevant data protection legislation, as well as from information published on Eircom's website.

Under the terms of the settlement, the signatory record companies are responsible for making infringement allegations. They have engaged DtecNet- the same company as was involved in iiNet - to monitor P2P networks on their behalf. ${ }^{207}$ When an infringement appears to occur at an IP address associated with an Eircom customer, it sends a notification to the ISP containing details of the allegation. ${ }^{208}$ Eircom passes it on to the relevant subscriber with the subscriber's regular bill. ${ }^{209}$ If the same subscriber is detected a second time (after a fourteenday grace period has elapsed), Eircom sends a second warning in a formal letter. ${ }^{210}$ If a third notice is received (after a further fortnight's grace period), the High Court explained that Eircom employees would manually "review all the evidence" and then give the customer notice that his access will be terminated. ${ }^{211}$ This seems inconsistent with a statement more recently made by Eircom's Director of Corporate Affairs, Paul Bradley, to the effect that Eircom does not investigate allegations, but rather simply matches the IP address to the relevant subscriber and

Bridy, Graduated Response American Style: 'Six Strikes' Measured Against Five Norms, 23 FORDHAM InTELl. Prop. MEdia \& ENT. L.J. 1 (2012); see also Mary LaFrance, Graduated Response by Industry Compact: Piercing the Black Box, 30 CARDOZO ARTS \& ENT. L.J. 165 (2012) (examining the U.S. scheme).

204. Tim Healy, Eircom May Face Music in Illegal Files Row, The IndePENDENT (Mar. 11, 2008), http://www.independent.ie/national-news/eircom-may-face-music-in-illegal-files-row-1313154. html.

205. EMI Records (Ireland) v. Eircom [2010] IEHC 108, IIII 1-2.

206. Eircom, eircom Statement on Illegal File Sharing (Dec. 8, 2010), http://pressroom.eircom.net/ press_releases/article/eircom_Statement_on_Illegal_File_Sharing/.

207. John Collins, Eircom to Cut Broadband over Illegal Downloads, IRISH TIMES (May 24, 2010) http://www.irishtimes.com/newspaper/frontpage/2010/0524/1224271013389.html.

208. EMI Records (Ireland) v. Eircom [2010] IEHC 108, II 9; Eircom, supra note 206.

209. EMI Records (Ireland) v. Eircom [2010] IEHC 108, II 13.

210. Id.

211. Id. 
issues the notice. ${ }^{212}$

Once a termination notice has been issued, the High Court indicates, the subscriber can make representations to Eircom regarding extenuating circumstances that justify waiver of the penalty, or seeking to prove that the infringements did not occur as alleged. ${ }^{213}$ The overview of the protocol published on Eircom's website omits this step, and since the protocol itself is not available to the public, it is unclear whether it remains part of the arrangement. According to Bradley, there is, in fact, no avenue of appeal. ${ }^{214}$ Assuming that an informal right of appeal does exist, if no such representations are made (or if they are not accepted by Eircom), Internet access will be withheld. The scheme, as described by the High Court, originally provided for permanent termination of the subscriber's Internet access. ${ }^{215}$ This was subsequently amended: under the revised scheme, a seven-day account suspension is to be imposed after a third notification, and a twelve-month suspension after a fourth. ${ }^{216}$ Eircom's power to suspend or terminate access arises by virtue of a clause in its standard form subscriber contract. ${ }^{217}$ Subscription fees are waived or refunded during periods of suspension. ${ }^{218}$ The program was formally launched in December 2010, ${ }^{219}$ following a pilot program which ran from May of that year. ${ }^{220}$

As the High Court itself pointed out, the settlement was likely to have a negative effect on Eircom: "it [i]s likely to be deeply unfair that only Eircom with about $40 \%$ of the market share . . . should bear the burden of this settlement, thus activating the winds of market forces to drive customers towards Eircom's competitors." 221 In recognition of this, the record industry agreed to initiate proceedings against other ISPs. ${ }^{222}$ However, this has not resulted in any adverse findings or any other ISPs agreeing to an Eircom-style private graduated response, and Justice Peter Charleton ruled in 2010 that there is currently no legal obligation for ISPs to implement their own "three strikes" regimes. ${ }^{223}$

Due to its origin in litigation instituted by the recording industry, the Irish scheme is quite narrow. Not only is it limited in operation to just one ISP, but it extends only to infringement allegations made by the parties to the settlement,

212. Telephone Interview with Paul Bradley, Director of Corporate Affairs, Eircom (Sept. 7, 2012) (contemporaneous notes of conversation on file with author).

213. EMI Records (Ireland) v. Eircom [2010] IEHC 108, đ 13.

214. Telephone Interview with Paul Bradley, Director of Corporate Affairs, Eircom (Sept. 7, 2012) (contemporaneous notes of conversation on file with author).

215. EMI Records (Ireland) v. Eircom [2010] IEHC 108, II 13.

216. Eircom, supra note 206.

217. EMI Records (Ireland) v. Eircom [2010] IEHC 108, II 14.

218. Legal Music Frequently Asked Questions, EIRCOM (2012), http://www.eircom.net/notification /legalmusic/faqs.

219. Cían Nihill, Illegal Music Downloaders Face Cut-Off, Eircom Warns, IRISH TIMES (Dec. 9, 2010) http://www.irishtimes.com/newspaper/ireland/2010/1209/1224285100549.html.

220. Collins, supra note 207.

221. EMI Records (Ireland) v. Eircom [2010] IEHC 108, II 10.

222. Id.

223. EMI Records (Ireland) v. UPC Communications Ireland [2010] IEHC 377. 
including the Irish branches of the EMI, Sony, Universal and Warner record labels. ${ }^{224}$ Eircom does not pass on any allegations of infringement made by other rights holders. ${ }^{225}$ The costs of issuing notices and terminating users are borne by the ISP.

\section{b. Application So Far}

It is unclear how many users have been affected by the Eircom scheme, because the confidential nature of the settlement agreement means that information is not available to the public. However, EMI Ireland Chief Executive Willie Kavanagh apparently disclosed some of this data in a meeting with the Minister of State for Research and Innovation in December 2011, claiming that Eircom had issued 29,000 individual letters, and that " 100 customers had reached the fourth stage of losing their access for one week and 12 customers are at the stage where they will be permanently cut off by Eircom." 226 Despite this claim, an Eircom representative stated in September 2012 that the ISP had not suspended any user for longer than a week. $^{227}$

Implementation of the scheme has not been entirely smooth. Although the settlement was cleared by the High Court as complying with the relevant data protection legislation, ${ }^{228}$ the Data Protection Commissioner announced an investigation into the scheme just six months after it formally launched, following revelations that basic technical errors had led to 391 subscribers being incorrectly identified as infringers and issued with notices. ${ }^{229}$ In January 2012, the Commissioner issued an enforcement order to Eircom requiring it to cease disconnecting users. ${ }^{230}$ In June 2012, this was overturned by Mr. Justice Charleton, the same High Court judge who originally cleared the settlement, who found the Commissioner's notice invalid for failing to give sufficient reasons. ${ }^{231}$ His decision was subsequently upheld by the Supreme Court. ${ }^{232}$

224. Telephone Interview with Paul Bradley, Director of Corporate Affairs, Eircom (Sept. 7, 2012) (Contemporaneous notes of conversation on file with author).

225. Id.

226. Eamonn Laird, Note of Minister Sherlock's Meeting with the Irish Recorded Music Association on Monday 5th December 2011, SCRIBD (Dec. 7, 2011), www.scribd.com/doc/83984745/ EMI-Briefing-001.

227. Telephone Interview with Paul Bradley, Director of Corporate Affairs, Eircom (Sept. 7, 2012) (contemporaneous notes of conversation on file with author).

228. EMI Records (Ireland) v. Eircom [2010] IEHC 108, III 2, 43.

229. See EMI Records (Ireland) v. The Data Protection Commissioner [2012] IEHC 264, IfII 1.31.4 .

230. The notice has not been separately published but is extracted in Mr. Justice Charleton's judgment. EMI Records (Ireland) v. The Data Protection Commissioner [2012] IEHC 264, IIII 4.0-4.1.

231. EMI Records (Ireland) v. The Data Protection Commissioner [2012] I.E.H.C. 264, II 14.

232. See EMI Records (Ireland) v. The Data Protection Commissioner [2013] IESC 34. 


\section{The United States}

\section{a. The Law}

The most comprehensive and widespread privately-arranged graduated response is the one that recently came into operation in the United States. It took a long and winding road to implementation, with rights holders and ISPs in negotiations for some three years (reportedly with some involvement of the White House) ${ }^{233}$ before the deal was finally reached. ${ }^{234}$ In July 2011, it was announced that a stable of the largest ISPs would collaborate with rights holders such as the MPAA and the RIAA to create a graduated response regime based on a system of "copyright alerts." 235 After repeated delays, ${ }^{236}$ the scheme was finally implemented on February 25, 2013. ${ }^{237}$

The organization charged with administering the scheme is the Center for Copyright Information (CCI), which is governed by a six-member "executive committee" comprising an even split of content and ISP industry representatives. ${ }^{238}$ Funding to run the CCI is provided by participating content owners and ISPs in equal shares. ${ }^{239}$ Three consumer representatives are permitted on a separate "Advisory Board," but their opinions and contributions have no authority over the Executive. ${ }^{240}$ The scheme is limited in scope to alleged infringements facilitated by P2P file sharing technologies. ${ }^{241}$ Thus, it does not apply to infringements committed via online file lockers, message boards and other non-P2P technologies.

The U.S. process is set out in detail in the publicly available Memorandum of Understanding reached between the parties (as occasionally amended). ${ }^{242}$

233. Matthew Lasar, Big Content, ISPs Nearing Agreement on Piracy Crackdown System, ARS TECHNICA (Jun. 24, 2011, 1:25 PM), http://arstechnica.com/tech-policy/2011/06/big-content-ispsnearing-agreement-on-piracy-crackdown-system/.

234. Bridy, Graduated Response American Style, supra note 203, at 10.

235. Greg Sandoval, Top ISPs agree to become copyright cops, CNET (Jul. 7, 2011, 8:39 AM), http://news.cnet.com/8301-31001_3-20077492-261/top-isps-agree-to-become-copyright-cops/.

236. The scheme was originally anticipated to start operating in 2011. See Music, Movie, TV and Broadband Leaders Term to Curb Online Content Theft, ReCoRDING InDus. Ass'N AM. (July 2011), http://www.riaa.com/newsitem.php?content_selector=newsandviews\&news_month_filter=7\&news_year _filter=2011\&id=2DDC3887-A4D5-8D41-649D-6E4F7C5225A5. This was subsequently pushed back to July 1, 2012, Greg Sandoval, RIAA chief: ISPs to Start Policing Copyright by July 1, CNET (Mar. 14, 2012), http://news.cnet.com/8301-31001_3-57397452-261/riaa-chief-isps-to-start-policing-copyright-by -july-1; and then again to the end of 2012, see, e.g., Cyrus Farivar, Six Strikes' Internet Warning System Will Come to US this Year, ARS TECHNICA (Sept. 12, 2012), http://arstechnica.com/techpolicy/2012/09/six-strikes-internet-warning-system-really-truly-coming-to-us-this-year.

237. Jill Lesser, Copyright Alert System Set to Begin, CTR. FOR COPYRIGHT INFO. (Feb. 25, 2013), http://www.copyrightinformation.org/uncategorized/copyright-alert-system-set-to-begin.

238. CTR. FOR COPYRIGHT INFO., MEMORANDUM OF UNDERSTANDING 3 (July 6, 2011), available at http://www.copyrightinformation.org/wp-content/uploads/2013/02/Memorandum-of-Understanding. pdf.

239. Id. at 4 .

240. Id. at 3-4.

241. Id. at 2 .

242. See id.; Ctr. FOR COPyright Info., MEMORAndum OF Understanding (FIRST 
When a participating content owner believes that its copyright has been infringed by a subscriber of a participating ISP (as determined by IP address), it may send an allegation to the relevant ISP. ${ }^{243}$ The ISP then matches the IP address to the subscription account to which it was assigned at the time of the alleged infringement. After that, the ISP's actions depend on whether and when any previous allegations have been made against that account.

The first time an ISP receives a notice associated with a particular subscriber's account, it is required to dispatch an "Educational Step Copyright Alert."244 This informs the subscriber of the allegation and, among other things, reminds him that his account is not permitted to be put to infringing use, lets him know that there are legitimate ways of obtaining copyright protected content, and warns him that continued infringement may result in the imposition of mitigation measures or other sanctions permitted under the subscription agreement. ${ }^{245}$ Subscribers are not required to take any action in response to educational alerts.

If a second allegation is made against a subscriber account, the ISP may (at its option) issue a second Educational Step Copyright Alert in the same manner as described above, or it may move on to the "Acknowledgement Step." 246 Most commentators have assumed that, in practice, ISPs will indeed issue two educational notices, and this Article makes the same assumption. If that is the case, then ISPs will enforce the Acknowledgement Step for any third and fourth allegations. These alerts differ from the previous step in that they "require acknowledgement of receipt," perhaps by diversion to a "landing page" or via a pop-up notice. ${ }^{247}$ Although users are not required "to acknowledge participation in any allegedly infringing activity," they are required to "agree . . . immediately to cease, and/or agree . . . to instruct other users of the Subscriber's account to cease infringing conduct." 248

A fifth allegation against a subscriber's account may result in an ISP issuing a "Mitigation Measure Copyright Alert." This requires notification to the subscriber that, unless they seek review under the scheme's appeal process, a mitigation measure will be applied to their account. ${ }^{249}$ ISPs have considerable discretion in determining the scope of mitigation measure to impose. A nonexhaustive list of possibilities includes reductions of upload and download speeds, account downgrades, or “temporary restriction of the Subscriber's Internet access for some

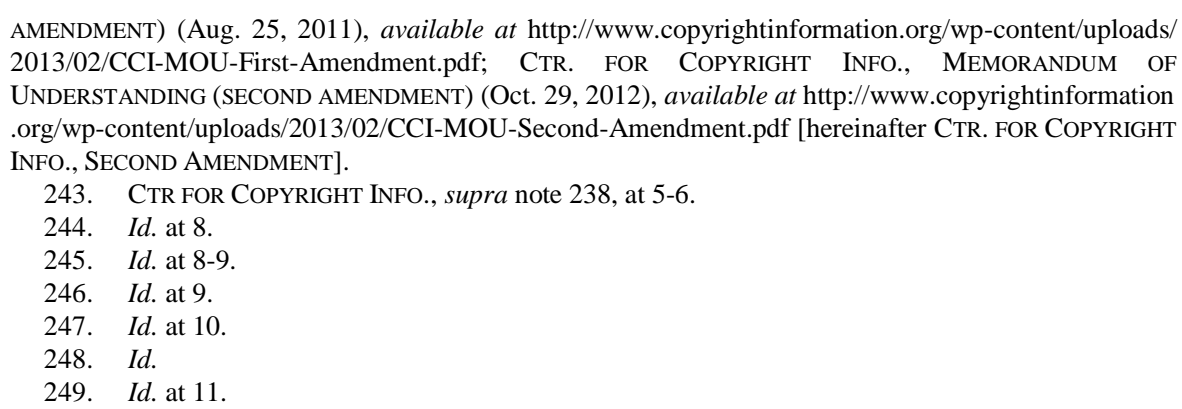


reasonable period of time as determined in the Participating ISP's discretion."250 The ISP may choose to waive the mitigation measure once per account. ${ }^{251}$ At this point, the subscriber would receive a "final warning," informing her that if another allegation is received, a mitigation measure will be imposed.252 If a subsequent allegation is made, the ISP must impose a mitigation measure. ${ }^{253}$ If yet another allegation is made after that, the ISP must impose a further mitigation measure (which may be the same as before, or a different variation) and notify the account holder that she may be sued for copyright infringement, or have her Internet access suspended or terminated under the ISP's terms of service. ${ }^{254}$

There are no further graduations after this step. ISPs may choose to pass on any further notices to the subscriber, but have no obligation to do so. They must, however, maintain records regarding the number of notices received in relation to that subscriber's account, and report that information to rights holders. ${ }^{255}$ To give account holders an opportunity to take steps to prevent infringement, there is a seven-day "grace period" after the issue of each notice. ISPs may choose to pass on infringement allegations made during this time, but they will not count for the purposes of moving forward in the enforcement program. ${ }^{256}$ If an ISP does not receive a subsequent infringement allegation relating to a subscriber account for twelve months after the previous one, the system resets: regardless of how far the process had progressed, the next notice will be treated as the first to be issued. ${ }^{257}$

Subscribers may request "independent review" of their $\operatorname{cases}^{258}$ via a scheme administered by the American Arbitration Association. ${ }^{259}$ Perhaps to avoid the perception that it is usurping the role of the judiciary, the Memorandum of Understanding (as amended) provides that:

[t]his Independent Review process does not prevent Subscribers or Copyright Owners from addressing disputes through the courts, and that is the proper forum for addressing issues that are beyond the scope of this Independent Review process. ${ }^{260}$

Three key restrictions limit each subscriber's right of review. First, review cannot occur until a subscriber has been advised that a mitigation measure is pending - even if the subscriber's complaint concerns an earlier notice. ${ }^{261}$ Second, the subscriber must pay a fee of $\$ 35.262$ Third, the subscriber must lodge the

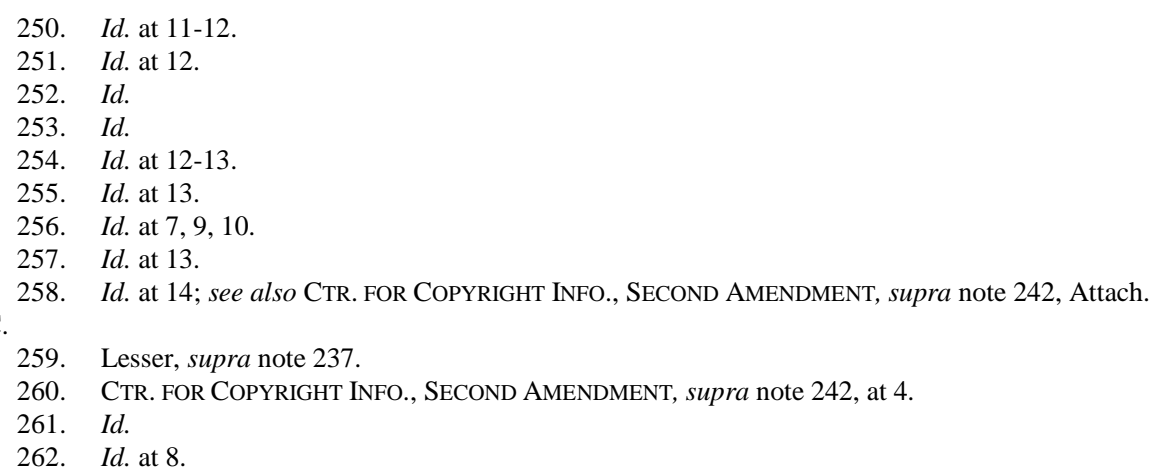


prescribed "Application to Commence Independent Review" form, materials in support of his defense and a filing fee within fourteen calendar days of the Mitigation Measure Copyright Alert being issued. ${ }^{263}$ Failure to do so "shall be deemed a waiver of the right to seek Independent Review."264 The brevity of this appeals window, particularly in light of the complexity of the relevant law, is one of the EFF's key criticisms of the scheme. ${ }^{265}$

If the review is of the first mitigation measure to be imposed on a subscriber, the subscriber may seek review of all previous alerts. ${ }^{266}$ If it concerns a subsequent mitigation measure, the subscriber may only challenge the notice that triggered that measure. ${ }^{267}$ There are six possible defenses that a subscriber may raise in relation to each alert: (1) Misidentification of account-i.e., when a factual error was made regarding the identification of the IP address to which the infringement related, or in matching that address to the subscriber. ${ }^{268}$ (2) Unauthorized use of account:

[a] Subscriber shall prevail on this defense if the Subscriber adequately and credibly demonstrates that the alleged activity was the result of unauthorized use of the Subscriber's account by someone who is not a member or invitee of the household (e.g. via an unsecured wireless router or a hacked Internet connection) of which the Subscriber was unaware and that the Subscriber could not reasonably have prevented. ${ }^{269}$

A subscriber can generally rely on this defense only once. ${ }^{270}$ (3) That the use of the material was "specifically authorized" by the Copyright Owner or their agent. ${ }^{271}$ (4) That the alleged infringement was actually fair use under "prevailing principles of copyright law."272 (5) That the file was misidentified:

A Subscriber shall prevail on this defense if the Subscriber adequately and credibly demonstrates that a factual error was made in identifying the file at issue as consisting primarily of the alleged copyrighted work. In making this determination, the Content Owner Representative Methodology used to identify the file shall have a rebuttable presumption that it works in accordance with its specifications . . . ${ }^{273}$

And (6) That the work was published before 1923. ${ }^{274}$

As the EFF notes, "there are many other possible defenses available in a

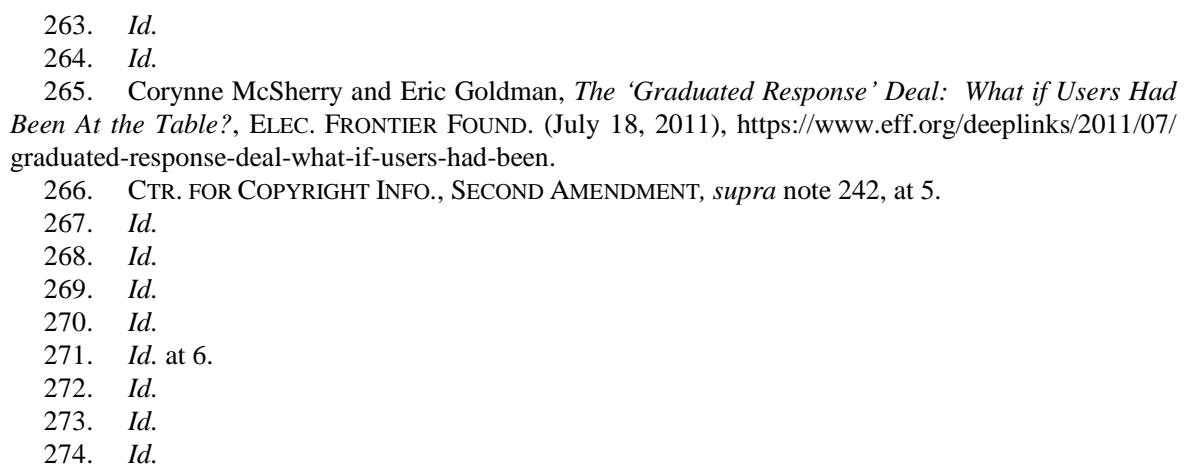


copyright litigation," and "even the six enumerated defenses are incomplete. For example, the 'public domain' defense applies only if the work was created before 1923 - even though works created after 1923 can enter the public domain in a variety of ways." 275 However, any non-infringing use that falls outside of the above defenses will not result in a subscriber succeeding in his appeal.

Subscribers seeking to prevail on one of these defenses must bring evidence to support their cases-there is no presumption of innocence. However, various presumptions do exist in favor of the rights holders and ISPs administering the scheme. One of the most significant is the presumption that the technologies and methodologies that provide the foundation of infringement allegations work as specified unless an independent expert finds them inadequate, ${ }^{276}$ though even then the underlying methodologies themselves will be kept confidential. ${ }^{277}$ Initially, infringement allegations will be generated by MarkMonitor (the new owner of DtecNet, the company that was also responsible for the alerts at issue at iiNet and under the Irish scheme). ${ }^{278}$ The "independent expert" initially appointed to review its technology was the firm of Stroz Friedberg. ${ }^{279}$ However, its independence was thrown into doubt after the discovery of an undisclosed link between the firm and RIAA lobbying, which triggered widespread cynicism about the process. ${ }^{280}$ The CCI has acknowledged the controversy and will select a replacement. ${ }^{281}$

For a subscriber to successfully avoid imposition of a first mitigation measure, "the Reviewer must find in favor of the Subscriber for at least half of the previously issued Copyright Alerts (i.e., two of four, or three of five)." ${ }^{282}$ To avoid a second mitigation measure, the Reviewer must find that a defense applies with regard to the allegation that triggered that measure. ${ }^{283}$ If the subscriber prevails, the filing fee will be refunded, record of the alerts will be removed from the account and the mitigation measure will not be imposed. ${ }^{284}$ If the subscriber does not successfully prove that half or more of the notices should be set aside, the threatened mitigation measure will be applied. ${ }^{285}$

275. Corynne McSherry and Eric Goldman, supra note 265.

276. CTR. FOR COPYRIGHT INFO., SECOND AMENDMENT, supra note 242, at 5.

277. See generally CTR. FOR COPYRIGHT INFO., supra note 238, at 5.

278. See MarkMonitor Acquires DtecNet: Acquisition Extends Anti-Piracy Capabilities for Digital Content, MARKMONITOR (Oct. 18, 2010), https://www.markmonitor.com/pressreleases/2010/ pr101018.php.

279. Lesser, supra note 237.

280. Jill Lesser, CCI Recommits to Independent Evaluation of Content Methodology, CTR. FOR COPYRIGHT INFO., http://www.copyrightinformation.org/uncategorized/cci-recommits-to-independentevaluation-of-content-methodology (last visited Nov. 18, 2013).

281. Id. The CCI also subsequently made a heavily redacted version of the Stroz Friedberg report available to the public. See STROZ FrIEDBERG, Ctr. for Copyright Info., IndEPENDENT ExPERT ASSESSMENT OF MARKMONITOR ANTIPIRACY METHODOLOGIES [REDACTED] (Nov. 1, 2012), available at http://www.copyrightinformation.org/wp-content/uploads/2012/12/Independent-Expert-AssessmentContent-CCI-Redacted.pdf.

282. CTR. FOR COPYRIGHT INFO., SECOND AMENDMENT, supra note 242, at 5.

283. Id.

284. Id. at 6-7.

285. Id. at 7 . 


\section{b. Application So Far}

There is very little information available about the application of the U.S. program in its first six months of operation. The CCI's most recent update on the matter was posted after the program had been running for almost three months. ${ }^{286}$ It confirmed that "[e]ach ISP has been processing notices and generating Alerts and the few consumers who have elected to challenge their Alerts have been able to file those challenges with the American Arbitration Association."287 No numbers have yet been provided regarding the number of notices issued, with the CCI simply stating that it planned to "provide further updates to the public" after it had had "sufficient time to thoroughly evaluate the program." 288 The CCI's response to the USPTO's call for submissions regarding whether initiatives such as the U.S. graduated response scheme have helped reduce infringement, made six months after implementation, was similarly light on data, providing no numbers about notices at all. ${ }^{289}$ The submission of the Independent Film \& Television Alliance, which participates in the "six strikes" arrangement, stated that "numerical data is not yet publicly available," hinting that data has been collected which the controlling organizations do not yet wish to release. ${ }^{290}$

\section{ARE GRADUATED RESPONSES FURTHERING THE AIMS OF COPYRIGHT LAW?}

The above descriptions of the various regimes raise obvious issues regarding lack of due process, privacy, transparency, accuracy and proportionality. These have been comprehensively explored elsewhere and this Article will not rehash that ground. 291 Instead, its focus is on identifying, synthesizing and evaluating the

286. Jill Lesser, Early Reports: CAS Moving Forward, CTR. FOR COPYRIGHT INFO., http://www. copyrightinformation.org/uncategorized/early-reports-cas-moving-forward/ (last visited Nov. 18, 2013).

287. Id.

288. Id.

289. CENTER FOR COPYRIGHT INFORMATION RESPONSE TO REQUESTS FOR COMMENTS: JOINT Strategic Plan for Intellectual Property Enforcement, Voluntary Best Practices Study 5-6 (2013), available at http://www.uspto.gov/ip/officechiefecon/PTO-C-2013-0036.pdf.

290. INDEPENDENT FILM \& TELEVISION ALLIANCE RESPONSE TO REQUESTS FOR COMMENTS: Joint Strategic Plan for Intellectual Property Enforcement, Voluntary Best PRactices STUDY 4 (2013), available at http://www.uspto.gov/ip/officechiefecon/PTO-C-2013-0036.pdf (emphasis added).

291. This paper does not purport to deal with these issues, but they have been comprehensively dealt with elsewhere. See, e.g., Nicolas Suzor and Brian Fitzgerald, The Legitimacy of Graduated Response Schemes in Copyright Law, 34(1) UNIV. NEw S. WALES L.J. 1 (2011) (arguing that a number of existing graduated response regimes fail to comply with key tenets of the rule of law); Bridy, Graduated Response American Style, supra note 203, at 1 (evaluating the U.S. graduated response law); Special Rapporteur, Report on the promotion and protection of the right to freedom of opinion and expression, Human Rights Council, U.N. Doc. A/HRC/17/27 (May 16, 2011) (by Frank La Rue), available at http://www2.ohchr.org/english/bodies/hrcouncil/docs/17session/A.HRC.17.27_en.pdf (criticizing graduated response laws that provide for disconnection of access as being “disproportionate"); Peter K. Yu, The Graduated Response, 62 FLA. L. REV. 1373, 1416 (2010) (noting 
evidence of the effects of the various graduated response schemes in order to determine the extent to which they are achieving any of the copyright law's aims. As discussed in Part I, it is impossible to identify any one unifying aim or rationale. Accordingly, this analysis seeks to evaluate the extent to which the global graduated response is helping to achieve any of several distinct aims that are often put forward to justify the grant and expansion of copyright, while being agnostic as to which, if any, should be preferred. Thus, it asks: (1) To what extent do graduated responses reduce infringement? (2) To what extent do graduated responses maximize authorized uses? And (3) To what extent do graduated responses promote learning and culture by encouraging the creation and dissemination of a wide variety of creative materials?

\section{A. To What EXTENT Do GRAduATED RESPONSES REDUCE INFRINGEMENT?}

This section makes a jurisdiction-by-jurisdiction examination of the evidence that has been put forward to suggest that graduated response reduces infringement. In recognition of the fact that most graduated responses have been operating for two years or more, the focus is on actual results, not studies asking participants to hypothesize how they would react if they received a notice of infringement. The UK law is obviously omitted from this evaluation as it has not yet come into operation.

\section{France}

As evidenced by the number and nature of enforcement actions to date, the HADOPI system has been slow to identify and process repeat infringers. As discussed above, in the law's first three years of operation, just four subscribers were prosecuted, and only three of those were convicted. ${ }^{292}$ None of those prosecutions alleged actual infringement, only failure to appropriately secure Internet connections. ${ }^{293}$ Fines have been small, and access suspension was imposed only once before the partial repeal abolished that remedy in negligence cases. $^{294}$ The limited penalties imposed by the courts indicate that even those who were finally prosecuted were far from the most egregious cases. By contrast, the French culture minister originally suggested that the scheme would result in one thousand disconnections per day. ${ }^{295}$ One possible explanation for the dearth of enforcement action is that the system has worked extremely well, by massively reducing infringement. This section tests the evidence to consider whether that

\footnotetext{
the general failure of graduated response regimes to view the amount of infringement relative to the amount of legal use).

292. See discussion supra Part II.A.1.b.

293. Id.

294. Id.

295. France, the First Country to Implement the Controversial 'Three-Strikes-and-You're-Out' Legislation, EPM MuSIC (June 17, 2009), http://epm-music.com/digital-distribution/news/47-france-thefirst-country-to-implement-the-controversial-three-strikes-and-you-re-out-legislation.
} 
might be the case.

Some of the strongest claims that HADOPI reduces infringement have come from the Hadopi administrative body. In a report on its first one and a half years of operation, it cited four separate studies conducted between October 2010 and December 2011. Two of the figures claimed that P2P "audience levels" had declined because of Hadopi (by $17 \%$, according to one, and $29 \%$ according to the other); the other two figures claimed reductions of "illegal data sharing" of between $43 \%$ and $66 \% .{ }^{296}$

There is quite a lot to unpack in those claims. To start, the assertion of a $17 \%$ reduction in the $\mathrm{P} 2 \mathrm{P}$ audience was attributed to Nielsen/IFPI, and the source is listed as the "Digital Music Report 2012."297 IFPI publishes a "Digital Music Report" each year, but its 2012 report makes no such assertion. Instead, with regard to the French regime, it actually claims (in several places) that the number of P2P file sharers fell by $26 \% .^{298}$ No methodology is provided to explain how this figure was reached. Oddly, in its 2013 report, published a full year after Hadopi first cited that figure, ${ }^{299}$ IFPI did claim that Hadopi brought about a $17 \%$ reduction in infringement. ${ }^{300}$ However, as it did not provide any authority for that number either, its provenance cannot be determined.

The second figure quoted in the Hadopi report, claiming a 29\% reduction in audience levels, is attributed to Médiamétrie//NetRatings - a French audience measurement company which is affiliated with Nielsen and uses its NetSight computer monitoring technology. ${ }^{301}$ As noted above, Nielson apparently worked in conjunction with IFPI to develop the figures referred to above. The report does not appear to be publicly available, and a request for access went unanswered. ${ }^{302}$ The Hadopi report includes no details of the methodology used to derive the figures. Both Médiamétrie//NetRatings and Nielsen utilize metering software to measure network usage patterns, which means that their data only captures users who have freely agreed to have that software installed and their behavior tracked. ${ }^{303}$ Any change in behavior by users who are aware that their usage is being carefully monitored is unlikely to be representative of the general population.

The other two studies cited in the Hadopi report as evidence of the law's effect

296. HAUTE AUTORITE POUR LA DIFFUSION DES (EUVRES ET LA PROTECTION DES DROITS SUR INTERNET, HADOPI, 1 1/2 YEAR AFTER THE LAUNCH 3 (2012), http://www.hadopi.fr/sites/default/files/ page/pdf/note17_en.pdf.

297. Id. at 4 .

298. Int'l Fed'n Phonographic Indus., Digital Music Report 2012 9, 17 (2012), available at www.ifpi.org/content/library/dmr2012.pdf.

299. IFPI Publishes Digital Music Report 2013, InT'L FED'N PHONOGRAPHIC Indus. (Feb. 26, 2013), http://www.ifpi.org/content/section_resources/dmr2013.html (announcing the release of the 2013 report). By contrast, the Hadopi report was published in March 2012. See HAUTE AUTORitÉ, supra note 296 at 16.

300. Int'l Fed'n Phonographic Indus., supra note 6, at 30.

301. Médiamétrie//NetRatings Panel, MÉDIAMÉTRIE, http://www.mediametrie.com/internet/ solutions/mediametrie-netratings-panel.php?id=8 (last visited Nov. 20, 2013).

302. The request was made by email on Jun. 4, 2013 (on file with author).

303. HAUTE AUTORITE, supra note 296, at 7. 
on infringement were conducted by Peer Media Technologies and Association de Lutte Contre la Piraterie Audiovisuelle (ALPA), and claimed reductions of "illegal data sharing" of $43 \%$ and $66 \%$, respectively. ${ }^{304}$ Peer Media Technologies describes itself as a "world wide leader in anti-piracy services." 305 Its core business is being hired to identify apparent infringers and then issue customized infringement notices. ${ }^{306}$ Once again, repeated requests seeking access to its report elicited no response. ${ }^{307}$ ALPA is the French affiliate of the MPAA, and has a strong vested interest in promoting global adoption of graduated response in pursuit of its enforcement agenda. ${ }^{308}$ Its study does not appear to be publicly available either, nor is any information about the methodology used to reach the figures. ALPA's head has separately claimed that not a single French film was downloaded between May and December 2011 thanks to its enforcement efforts. ${ }^{309}$ The outlandishness of this claim further suggests that ALPA's figures should be viewed with caution.

Although Hadopi acknowledged that analyzing the law "is a complex endeavor and one to be undertaken cautiously," and that "[a] number of "marginal effects' remain difficult, if not impossible to quantify," 310 its use of these figures is open to criticism. Notably, every figure it cited in support of the claim that the French law reduces infringement was supplied by one or more organizations closely allied to the interests of major rights holders, and, in several cases, having a strong and obvious vested interest in promoting graduated response. None of them appear to have been subjected to peer review or have made their full reports or methodologies available for public scrutiny. The figures are headline-grabbing, but impossible to substantiate or evaluate in any meaningful way. It is also unclear whether any or all of those studies attempted to identify what proportion of any reduction was attributable to licensed services, like Spotify (a music streaming service which became widely available in France shortly after HADOPI came into operation $)^{311}$ or Deezer, an increasingly popular French music streaming service which experienced rapid growth over the same period. ${ }^{312}$ The impact of such services is far from negligible. As IFPI reported in its 2012 Digital Music Report, France experienced an increase in music subscription revenues of more than $90 \%$ in

304. Id. at 3 .

305. World Wide Leader in Anti-Piracy Services, PEER MEDIA TeCHNOLOGIES, http://peermediatech.gja07.com (last visited Nov. 11, 2013).

306. Notification Services, PEER MEDIA TECHNOLOGIES, http://peermediatech.gja07.com/ notification.html (last visited Nov. 11, 2013).

307. Requests were made by email on Oct. 25, 2012 and Nov. 7, 2012 (on file with author).

308. Around the World, Motion PicturE ASS'N AM., http://www.mpaa.org/about/around-theworld (last visited Nov. 11, 2013).

309. Marc Rees, Entre le 15/05 et le 15/12/11, aucun film français téléchargé sur le Web, PC INPACT (May 24, 2012), http://www.pcinpact.com/news/71129-nicolas-seydoux-gaumont-alpa-hadopi. htm.

310. HAUTE AUTORITE, supra note 296, at 2.

311. Spotify Now Available to Everyone in France, SPOTIFY (Feb. 1, 2010), http://www.spotify. com/us/blog/archives/2010/02/01/spotify-disponible-pour-tous-en-france.

312. Pascal Rozat, Deezer: Profitability Down the Line?, InA Global (Aug. 19, 2011), http:// www.inaglobal.fr/en/music/article/deezer-profitability-down-line?tq=4 . 
the first eleven months of $2011 . .^{313}$

Notice volume data has also often been used to support the contention that Hadopi reduces infringement. As noted above, as of the end of July 2013, Hadopi had issued 2,004,847 first notices and 201,288 second notices, and there have been 710 "délibérations," or investigations, to see whether subscribers who have received a third allegation should be referred to prosecutors. ${ }^{314}$ There is clearly a striking difference between the number of users receiving a second notice compared to a first, and entering into the third phase compared to the second. The same pattern is exhibited by previously published volume data. ${ }^{315}$ It has been repeatedly argued that the discrepancy is proof that HADOPI reduces infringement. In the words of the Hadopi Commission's President, "[ $t$ ]he less third warnings we send ... the more the law will have proven effective." 316 The recording industry has also repeatedly cited the difference between the number of users who receive a first notice and the number who receive a second as evidence that the scheme is working. In its submission to New Zealand's graduated response fee review, Rianz stated: "[t]here is evidence that P2P levels have reduced dramatically . . . . According to Hadopi, as many as $95 \%$ of first notices from Hadopi do not give rise to a second notice; $92 \%$ of second notices do not give rise to a third." 317 IFPI has used the same trick, noting that "Hadopi has now sent more than one million notices, with only 8 per cent of infringers receiving a second warning." 318

However, the fact that fewer people receive subsequent notices than first notices does not mean that the issue of an earlier notice prevented subsequent infringing behavior. There are a number of other possibilities that might also explain the difference.

For one thing, a higher number of earlier than later notices will always be reflected in published figures because, by definition, subsequent notices cannot be issued to subscribers until after they have been issued with earlier ones. This creates an unavoidable time lag. Some idea about the extent of that lag can be gleaned from Hadopi's figures, which show that no second notices were issued until five months after the issue of the earliest first notices, and no délibérations (i.e., the third or enforcement stage) were undertaken until five months after the

313. Int'l Fed'n. Phonographic Indus., supra note 6, at 10.

314. Réponse graduée-Les chiffres clés, supra note 70.

315. See, e.g., NEwSLETTER, HADOPI, Dec. 2011, at 3, available at www.hadopi.fr/sites/default/ files/page/pdf/Hadopi_Newsletter12_2011.pdf (stating that the agency had issued 750,000 first warnings, 63,000 second warnings, and that 150 individuals had reached the enforcement stage); NEWSLETTER, HADOPI, Jul. 2013, at 6 (stating that the agency had issued 1,839,847 first notices, 170,453 second notices, and that 599 individuals had reached the enforcement stage).

316. Aymeric Pichevin, France's HADOPI Sends Out Final Copyright Infringement Notices, But Many Are Critical, BILLBOARD (Jul. 19, 2011, 12:56 PM), http://www.billboard.biz/bbbiz/others/frances-hadopi-sends-out-final-copyright-1005282382.story.

317. Recording Indus. Ass'n of N.Z. \& Indep. Music N.Z., Copyright (InFringING FiLE SHARING) -FEE REVIEW para. 37 (Apr. 30, 2012), available at www.med.govt.nz/business/intellectualproperty/pdf-docs-library/copyright/notice-process/illegal-peer-to-peer-file-sharing-submissions-on-feereview-discussion/rianz.pdf (internal citation omitted).

318. Int'l Fed. Phonographic Indus., supra note 6, at 30. 
earliest second notices were sent. ${ }^{319}$ This suggests that it is reasonable to expect that users who have received an earlier notice will not receive a subsequent one for at least five months, even if they do not change their infringing behavior. This inevitable lag will always skew the numbers in favor of earlier notices, and must be controlled for before the numerical difference can be attributed to a possible reduction of infringement.

Another explanation for the higher number of earlier notices is that a second notice can only be issued to any given subscriber if a second allegation is made within six months of the first. ${ }^{320}$ After that period expires, Hadopi can only respond to an allegation of infringement by issuing another "first" notice. ${ }^{321}$ Similarly, a third "strike" can only arise within a year of the second. ${ }^{322}$ Thus it is entirely possible that, over the thirty-four months of operation covered by the figures, some users received more than one "first" or "second" notice, causing an over-representation of those numbers without actually suggesting any reduction of infringement. As Hadopi has not released information detailing how many subscribers received a first or second notice on more than one occasion, this factor cannot be controlled for.

Another explanation for the difference in notice volumes is that, if some infringers do change their behavior in response to receiving a notice, that change might simply mean making a switch to less easily detectable sources of infringement. The considerable evidence that this has been occurring in France (and elsewhere) is discussed below, in the section evaluating the extent to which graduated response maximizes authorized uses. ${ }^{323}$

In addition to these possible explanations, it is well worth doing some simple modeling to examine the mathematical foundation on which the notice volume data argument is built. There is evidence that Hadopi issues relatively few notices compared to the number of infringement allegations it receives. As noted above, the number of allegations that had been acted upon after thirty-four months of operation seems to reflect just $12 \%$ of the allegations that had been made in the scheme's first eight months alone. ${ }^{324}$ There is also some specific information in two of the decided cases about the total number of reports made regarding each infringement, separate from those which gave rise to the formal notices. In the case involving Rihanna's "Rude Boy," the subscriber had been the subject of almost 150 reports to Hadopi before the enforcement action was eventually brought, ${ }^{325}$ and in

319. Réponse graduée-Les chiffres clés, supra note 70.

320. Alain Strowel, The 'Graduated Response' In France: Is it the Good Reply to Online Copyright Infringements?, in COPYRIGHT ENFORCEMENT AND THE INTERNET 147, 149 (Irini A. Stamatoudi ed., 2010).

321. See discussion of the HADOPI system supra Part II.A.1.a.

322. Id.

323. See discussion infra Part III.B.

324. See report discussed supra Part II.A.1.b.

325. Marc Rees, Hadopi: condamné pour un seul titre, flashé 150 fois, PC INPACT (Oct. 7, 2012, 10:36 AM), http://www.pcinpact.com/news/74364-hadopi-condamne-pour-seul-titre-flashe-150-fois. htm. 
the case involving the "Heartbreaker" film, over 100 reports had been made. ${ }^{326}$ Thus it appears that only a very small proportion of infringements give rise to a first notice at all.

If we assume that subscribers who do receive a notice do not change their behavior in response, the probability of accruing two notices is exponentially lower, and the chance of receiving a third notice lower still. That's because, if there is no behavioral change, the chance of an individual receiving a subsequent notice is entirely independent of whether or not she had previously received one. To illustrate this, we will assume that individuals have a $12 \%$ chance of receiving a notice in any given period. (Hadopi has not released sufficient data to enable precise determination of the probability of that occurring, so this is an approximation based on the figures which are available, in order to demonstrate the principle.) Assume also that the individuals who receive notices do not change their infringing behavior after receiving them. In that case, they would have about a $1.44 \%\left(0.12^{2}\right)$ chance of being issued two notices, and less than a fifth of a percent chance $\left(0.12^{3}\right)$ of reaching the enforcement stage. Hadopi has not released precise numbers regarding the number of allegations made, which makes comparison with the number of notices actually issued impossible. However, we can apply the mathematical model to the numbers above. Given the issue of $2,004,847$ first notices, it could be anticipated that some 240,581 individuals would receive a second notice, ${ }^{327}$ even if none of the subscribers who received a notice changed their infringing behavior. The figures show that some 201,288 actually did. That is, only 39,293 individuals, or $16 \%,{ }^{328}$ of the number who received a first notice might plausibly have changed their behavior as a result of receiving it.

However, we have to refine the numbers a little further before considering the possibility that some of that $16 \%$ of subscribers actually changed their behavior in response to a notice. Remember, these calculations do not take into account the five-month time lag before repeat infringers can reasonably be expected to receive a second notice. We can approximately control for that by comparing instead the total number of first notices which had been issued by February 2013, five months before the second notice figures we've been working with, thus allowing the first and second notice figures to match up more accurately. Hadopi had issued 1,599,847 first notices by February 2013. ${ }^{329}$ Applying the same model as previously, if there was no change of behavior at all, it could be anticipated that 191,982 subscribers would receive a second notice by July $2013,{ }^{330}$ five months later. As noted above, a higher number, 201,288, actually did. Of course, the

326. Marc Rees, Hadopi: condamné pour un seul film, flashé plus de 100 fois, PC INPACT (Feb. 19, 2013, 5:40 PM), http://www.pcinpact.com/news/77604-hadopi-condamne-pour-seul-film-flasheplus-100-fois.htm.

327. $2,004,847$ multiplied by 0.12 .

328. 240,581 (the number of individuals who can have been expected to have received a second notice if we apply this mathematical model) minus 201,288 (the number of individuals who were actually reported as having received a second notice), which equals 39,293 , or $16.33254 \%$ of 240,581 .

329. Réponse graduée-Les chiffres clés, supra note 70 at 1.

330. $1,599,847$ multiplied by 0.12 . 
derivation of all of these outcomes is entirely dependent on the assumptions adopted. Hadopi hasn't released data that allows for a more accurate calculation of the time lag between notices, or of the precise chance of an infringer receiving a notice, and the exact data (if it was available) might significantly change these outcomes. ${ }^{331}$ However, working from the information that has been made publicly available, this analysis demonstrates that, if one is going to take anything from the notice volume data, it is that the amount of infringement committed between the issue of first and second notices might actually have increased.

The difference between the number of second notices, and the number of enforcement actions, is statistically much more significant. Applying our model, if no subscriber on their second strike changed their infringing behavior, we could reasonably expect 24,147 (201,288 multiplied by 0.12$)$ individuals to have reached the "délibération" stage. ${ }^{332}$ However, by July 2013, only 710 délibérations were actually reported. ${ }^{333}$ Even if we calculate the figures more accurately by controlling for the five-month time lag, and compare the second strikes as of February 2013 to the enforcement actions of July 2013, we could still reasonably expect some 16,674 individuals to have reached the final stage. ${ }^{334}$ The big difference between these figures and the actual number superficially invites a finding that a significant number of users on their second strike have changed their behavior. But again, the available data does not actually justify that conclusion. We do not know how long it takes Hadopi to commence and finalize each investigation. If this time period is lengthy, however, that could have a very significant impact on the numbers. We already know that Hadopi issued first notices for only a very small proportion of infringement allegations it received, presumably at least in part due to a lack of resources. ${ }^{335}$ And first notices are the easiest to deal with as they require relatively little human intervention. By contrast, the third phase requires a full investigation by the Commission. ${ }^{336}$ What is known is that Hadopi did not process its first délibérations until July 2011,337 and the first cases were not forwarded to prosecutors until February 2012, some eighteen months after the scheme commenced operation. ${ }^{338}$ Furthermore, data published by

331. Nor does the model take into account fluctuations in subscriber or Hadopi agency behavior month by month, as it is impossible to do so on the existing data. For example, Hadopi did not issue any notices in August 2011 or August 2012. This is likely because the employees were taking summer vacation, not because no infringements were occurring. No conclusions can be drawn, however, in the absence of further information.

332. Calculated as $12 \%$ of $1,839,847$ (the number of first notices issued in the first thirty-four months of operation).

333. Réponse graduée - Les chiffres clés, supra note 70, at 5.

334. 138,953 multiplied by 0.12 .

335. See discussion supra Part II.A.1.b.

336. See Strowel, supra note 320, at 150; Réponse graduée, HADOPI, http://www.hadopi.fr/usagesresponsables/nouvelles-libertes-nouvelles-responsabilites/reponse-graduee (last visited Nov. 13, 2013).

337. Réponse graduée - Les chiffres clés, supra note 70, at 5.

338. Emmanuel Berretta, EXCLUSIF-Les internautes traduits devant les parquets par la Hadopi, LE POINT (Feb. 13, 2012, 9:10 AM), http://www.lepoint.fr/chroniqueurs-du-point/emmanuel-berretta/ exclusif-les-internautes-traduits-devant-les-parquets-par-la-hadopi-13-02-2012-1430826_52.php. 
Hadopi in August 2013 shows that it has never processed more than 64 deliberations in a month. ${ }^{339}$ By contrast, in the same amount of time, it managed to dispatch as many as 103,989 first notices and 15,818 second notices. ${ }^{340}$ The theory that enforcement actions are highly labor-intensive gains support from the fact that, while the Agency dispatched first and second notices in August 2011 and 2012, the traditional vacation month in France, no enforcement actions were reported in August of either year. ${ }^{341}$ These facts combine to strongly suggest that resourcing limitations are restricting the number of investigations that the agency can undertake at any one time. In these circumstances, the relatively small number of délibérations does not, in and of itself, evidence any change in user behavior. Treating it as such assumes that Hadopi has infinite resources, which is clearly not the case, as is demonstrated by the relatively few infringement allegations Hadopi has acted upon. The fact that few investigations have occurred cannot be given any weight as proof of the regime's efficacy, without (at least) information regarding the number of allegations which are being made, the number which are being acted upon, the number of third allegations that have been made and the number of investigations waiting to be commenced.

In sum, the probabilistic relationship between actual infringement and notices issued means that a large discrepancy between the various types of notices would inevitably occur even if recipient subscribers did not change their infringing behavior at all. It is impossible to calculate the precise effect of this discrepancy in the absence of vital missing data, such as the number of infringements occurring compared to the number of allegations made, the number of allegations made compared to the number that Hadopi actually responds to, the precise time lag in issuing them and the number of users who received first or second notices multiple times. However, the mathematical modeling above, based on assumptions for which data is available, casts even more doubt on the claim that the discrepancy between the number of first and subsequent notices proves any reduction of infringement.

France has been described as "very much the gold standard for graduated response public law." 342 However, when the data is carefully considered, there is scant evidence that the law actually reduces infringement. Since the dearth of infringement actions in its first three years of operation cannot be explained by a reduction in infringement, the most likely remaining explanation is simply that it is not very well equipped to identify and process the most egregious repeat offenders.

\section{New Zealand}

IFPI has claimed that "P2P use in New Zealand fell by 16 per cent" after its

339. Réponse graduée - Les chiffres clés, supra note 70, at 5.

340. Id. at 1,3 .

341. Id. at $1,3,5$.

342. David J. Brennan, Quelling P2P Infringement: Private American Harbours or Public French Graduations?, 62 TeleCOMM. J. AuSTL. no. 4, 2012, at 55.1, 55.6. 
graduated response law was introduced. ${ }^{343}$ It provided no source for this figure. RIANZ cited IFPI-commissioned research to claim an $18 \%$ reduction in the use of P2P services (including legitimate services) in the seven months since the law was introduced, though it still found considerably more New Zealanders accessed online infringing services than the global average. ${ }^{344}$ The New Zealand Federation Against Copyright Theft ("NZFACT") 345 claimed that the number of major U.S. films shared by New Zealand users each month effectively halved when the law came into operation, before increasing slightly and then plateauing. ${ }^{346}$ Again, the underlying studies and methodologies on which these claims are based are not publicly available.

A much more transparent study was conducted by researchers at Waikato University. Although drawn from very limited data points, the study suggested that P2P traffic and the number of users engaged in P2P file sharing decreased by at least half after the law came into force. ${ }^{347}$ It also found the use of technologies that could be used to circumvent the scheme had jumped significantly, although this increase was less than the drop in overall file sharing. ${ }^{348}$ A follow-up by the same researchers in September 2012 found that, although the amount of P2P traffic had recovered somewhat, it was still well below the levels of the year before. ${ }^{349}$ However, as discussed in more detail below, it also found a massive increase in the amount of HTTPS traffic. ${ }^{350}$ HTTPS is a form of encryption which prevents traffic from being easily analyzed. The researchers theorized that this increase was caused by a shift towards non-P2P sources of infringement, which fell outside the scheme. 351

The researchers were frank about the limitations of their study, and did not claim that the observed changes were caused by New Zealand's graduated response law:

[T]hese results are from one New Zealand ISP only and merely indicate that there is a strong correlation between the [Copyright Amendment Act] and the behaviour that has been noted ... (not a causation!). To be able to form firmer conclusions, we would need to examine the traffic mixes for other ISPS [sic] both inside and outside

343. Int'l Fed'n Phonographic Indus., supra note 6, at 30.

344. Recording Indus. Ass'n of N.Z., supra note 317, paras. 63, 7.

345. This organization was recently renamed the "New Zealand Screen Association." See N.Z. SCREEN ASS'N, http://www.nzfact.co.nz/ (last visited Nov. 20, 2013).

346. Letter from Tony Eaton, Managing Director, New Zealand Federation Against Copyright Theft, to Ministry for Economic Development (May 1, 2012), 6-8, available at www.med.govt.nz/ business/intellectual-property/pdf-docs-library/copyright/notice-process/illegal-peer-to-peer-file-sharing -submissions-on-fee-review-discussion/nzfact.pdf.

347. Shane Alcock \& Richard Nelson, MEASuring THE IMPACT OF THE Copyright AMENDMENT ACT ON NEW ZEALAND RESIDENTIAL DSL USERS 2 (2012), available at https://secure. wand.net.nz/sites/default/files/caa.pdf.

348. Id.

349. The Impact of the Copyright Amendment Act: Update for September 2012, WAND NETWORK RES. GRP. (Oct. 25, 2012), http://wand.cs.waikato.ac.nz/content/impact-copyrightamendment-act-update-september-2012.

350. Id.

351. Id. 
New Zealand to determine whether the changes we observed are definitely related to the change in New Zealand law or simply reflect global Internet usage patterns. ${ }^{352}$

On balance, the Waikato research revealed some striking patterns and potentially suggested that there might have been a net reduction in infringement, but as the study's own authors noted, this does not mean that it was caused by the introduction of graduated response. Notably, neither it nor any of the rights holderfunded studies identified above appear to have controlled for the new services which were authorized by rights holders to provide legitimate content to New Zealanders around the same time as the new law. This omission could be very significant: the number of RIANZ-sanctioned digital music providers operating in the New Zealand market doubled shortly after the graduated response legislation was introduced. ${ }^{353}$

Despite the limitations of the available evidence, it was one of the factors which influenced the Minister of Commerce to leave the notice fee at $\$ 25$ after the sixmonth fee review, explaining: "[t]here has been a significant reduction in the volume of illegal file sharing in the first six months of the regime being in force. This suggests that the level of the fee has not initially prevented the regime from having the desired outcome." 354

\section{South Korea}

As Ian Hargreaves pointed out in the Digital Opportunity report, the South Korean experience is often cited by stakeholders "as an example of the success of stricter enforcement." 355 However, the data in support of that claim is thin. For example, after reporting results from the French HADOPI law, the IFPI's Digital Music Report 2012 simply claims that "[s]imilar positive indications come from South Korea," providing no evidence whatsoever in support. ${ }^{356}$ There appear to be no attempts to prove any causal connection between the Korean graduated response and reduced infringement.

\section{Taiwan}

Although the Taiwanese scheme has now been in operation for several years, there seems to be no evidence in the English language materials that any user has had his access suspended under the law, or any plausible evidence put forward to suggest it has brought about any reduction of infringement. Despite this, the IFPI

352. Id

353. Recording Indus. Ass'n of N.Z., supra note 317, para. 5.

354. Off. Minister of Comm., supra note 95, para. 4.

355. Ian Hargreaves, U.K. Intellectual Property Office, Digital Opportunity: A REVIEW of InTELlectual Property AND Growth 78 (May 2011), available at www.ipo.gov.uk/ ipreview-finalreport.pdf.

356. Int'l Fed'n Phonographic Indus., Digital Music Report 20129 (2012), available at www.ifpi. org/content/library/dmr2012.pdf. 
has cited Taiwan approvingly when reporting its successes on the graduated response front, ${ }^{357}$ and its efforts towards implementing graduated response were cited as a key reason for Taiwan's removal from the USTR's "special watch list" in 2009. ${ }^{358}$

\section{Ireland}

At the time of writing the Irish scheme has been in operation for almost three years. ${ }^{359}$ Along the spectrum of all of the graduated response schemes currently in existence, the Irish scheme has the fewest user safeguards, and seems to be the most heavily tilted in favor of rights holders. ${ }^{360}$ Nonetheless, there is no evidence that the arrangement has reduced the amount of infringement.

\section{The United States}

At time of writing, the U.S. scheme has been operating for just six months, so it cannot be expected that there will be much evidence yet regarding its efficacy. Nonetheless, the Obama Administration recently tasked the USPTO with determining "whether voluntary initiatives [such as 'six strikes'] have had a positive impact on reducing infringement."361 Describing this as "[c]onsistent with the Administration's policy of building a data-driven government," the USPTO invited comment from interested stakeholders to assist them in making such a determination, with responses due by August 2013. ${ }^{362}$ One of the questions the USPTO asked was whether there is "existing data regarding efficacy of particular practices, processes or methodologies for voluntary initiatives, and if so, what is it and what does it show?"363

It would be reasonable to expect that the Center for Copyright Information, which runs the scheme, would be best placed to provide evidence about what the scheme has achieved in its first six months of operation. However, it simply

357. See Int'1 Fed'n Phonographic Indus., IFPI Digital Music Report 201119 (2011), available at http://www.ifpi.org/content/library/DMR2011.pdf.

358. Press Release, Office of the U.S. Trade Representative, U.S.T.R. Announces Conclusion of the Special 301 Out-of-Cycle Review for Taiwan (Jan. 2009), http://www.ustr.gov/about-us/pressoffice/press-releases/2009/january/ustr-announces-conclusion-special-301-out-cycle-re.

359. Nihill, supra note 219, at 3 (announcing the December 2010 launch).

360. See Rebecca Giblin, Was the High Court in iiNet Right to Be Chary of a Common Law Graduated Response?, 18 MELB. U. MEDIA \& ARTS L. REV. (forthcoming 2013).

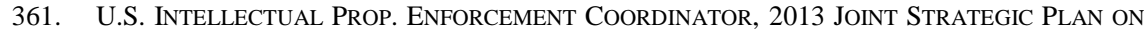
INTELlECTUAL PROPERTY ENFORCEMENT 37 (Jun. 2013), available at http://www.whitehouse.gov /sites/default/files/omb/IPEC/2013-us-ipec-joint-strategic-plan.pdf.

362. Request of the U.S. Patent and Trademark Office for Public Comments: Voluntary Best Practices Study, 78 Fed. Reg. 37, 210 (Jun. 20, 2013) (initial request for public comments); Extension of Comment Period for Request of the U.S. Patent and Trademark Office for Public Comments: Voluntary Best Practices Study, 78 Fed. Reg. 42,758 (Jul. 17, 2013) (extension of comment period to Aug. 21, 2013).

363. Request of the U.S. Patent and Trademark Office for Public Comments: Voluntary Best Practices Study, supra note 362. 
mentioned anecdotes about various account holders being "appreciative" of receiving infringement alerts, ${ }^{364}$ and stated that it was:

[E]ncouraged by the initial trends that show that its ISP participants are sending out a much larger number of first stage Alerts than later stage Alerts. If this trend continues, it may be an important signal that the Alert system is positively impacting user decisions going forward and that the CAS is helpful to consumers who receive Alerts. 365

No numerical data was provided in support of this statement. And of course, as discussed above in the context of the French system, differences between the number of first alerts and subsequent alerts by no means signals a reduction of infringement or achievement of any other of copyright's aims.

Other submissions in response to the USPTO's call were similarly devoid of data. MarkMonitor, the company responsible for generating the infringement allegations, provided a half-page response simply advertising its detection and monitoring services without addressing the efficacy of the "six strikes" arrangement at all. ${ }^{366}$ The MPAA praised "major Internet service providers, via the Copyright Alert System" for having "shown admirable willingness to enter into voluntary agreements and take concrete and effective anti-piracy measures." ${ }^{367}$ But despite its description of those measures as "effective," the MPAA submission later stated that it is "too soon to comment on the efficacy of the CAS." 368

This lack of data is not because no data exists. It is inconceivable that records are not being kept about the number of notices being issued, the number of repeat infringers, and the kind of infringements being detected. The existence of such data gets some confirmation from the submission of the Independent Film \& Television Alliance, which participates in the "six strikes" arrangement, to the USPTO. It stated that, "[w]hile the CAS is still in the early stages and numerical data is not yet publicly available, systems are in place to evaluate the effectiveness of the voluntary agreement and may be useful for future voluntary initiatives." 369

364. Jill Lesser, Comments of the Center for Copyright Information, Inc. 5-6 (Aug. 21, 2013), in U.S. PATENT AND TRADEMARK OfFice, COMMENTS REgarding USPTO's JoINT STRATEGIC Plan FOR InTELlECTUAL PROPERTY ENFORCEMENT VOLUNTARY BeST PRACTICES STUDY, available at http://www.uspto.gov/ip/officechiefecon/PTO-C-2013-0036.pdf\#page=39.

$365 . \quad I d$. at 6.

366. Kiran Malancharuvil, MarkMonitor Response to Request for Comments 1 (Aug. 21, 2013), in U.S. Patent AND TRADEMARK OfFice, COMMENTS REgarding USPTO's JoINT STRATEgic Plan FOR Intellectual Property Enforcement Voluntary Best Practices Study, available at http://www.uspto.gov/ip/officechiefecon/PTO-C-2013-0036.pdf\#page=136.

367. Benjamin Sheffner, Comments of the Motion Picture Association of America, Inc. 2 (Aug. 21, 2013), in U.S. PATENT AND TRADEMARK OfFICE, COMMENTS REGARDING USPTO's JoINT STRATEGIC

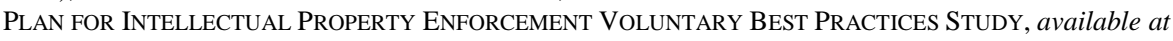
http://www.uspto.gov/ip/officechiefecon/PTO-C-2013-0036.pdf\#page=70.

368. Id. at 3 .

369. Jean Prewitt, IFTA Comments to Voluntary Best Practices Study 4 (Jul. 22, 2013), in U.S. Patent and TRAdemark OfFice, Comments Regarding USPTO's Joint STRATEGiC Plan fOR InTEllectual PROPERTy ENFORCEMENT VOLUntary BeSt PRACTICES STUdy, available at http://www.uspto.gov/ip/officechiefecon/PTO-C-2013-0036.pdf\#page=6 (emphasis added). 
This suggests that there is data, but that the controlling organizations do not wish to release it.

The RIAA expressed reluctance for the scheme to be measured at this point, suggesting instead that "[i]t may be appropriate for the government to delay measuring this program until it has been in operation for a reasonable period of time, and [the Center for Copyright Information] has had the opportunity to assess its impact." 370

These responses contain the best and most up-to-date data available at the time of writing. If there was any data suggesting that the U.S. scheme was having the desired effect, however, it is reasonable to expect that it would have been released. It is still early days, but the responses from stakeholders seem to confirm that there is currently no evidence in support of the U.S. scheme's efficacy.

Interestingly, Comcast is already pushing for the development of a different variety of ISP enforcement aimed at reducing infringement in U.S. markets. Comcast is a slightly unusual hybrid: not only is it a large ISP, it also has substantial media interests including ownership of Universal Pictures and the NBC television network. ${ }^{371}$ It has been reported that Comcast wants to implement technology "that would provide offending users with transactional opportunities to access legal versions of copyright-infringing videos as they're being downloaded." 372 Under the scheme, which Comcast has so far refused to confirm, infringers engaged in illegal downloading would apparently "be quickly pushed a pop-up message with links to purchase or rent the same content, whether the title in question exists on the [video on demand] library of a participating distributor's own broadband network or on a third-party seller like Amazon."373 In the absence of confirmation from Comcast, or any official details, it is difficult to gauge the feasibility of such a scheme. However, it does seem that this kind of approach would be much more directly focused on increasing the size of the legitimate market rather than simply reducing infringement.

\section{Conclusion}

When engaging in this kind of cross-jurisdictional, multi-language research, it is impossible to be sure that every relevant, quality resource has been identified. Some may have been overlooked. However, any resulting bias is not likely to

370. Victoria Sheckler, Comments of the Recording Industry Association of America, Inc. 3 (Aug. 17, 2013), in U.S. Patent and TRADEMARK OfFICE, Comments Regarding USPTO's Joint

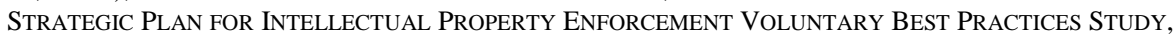
available at http://www.uspto.gov/ip/officechiefecon/PTO-C-2013-0036.pdf\#page=14.

371. Emma Woollacott, Comcast To Send Its Own Copyright Alerts, Forbes (Aug. 6, 2013, 8:20 AM), http://www.forbes.com/sites/emmawoollacott/2013/08/06/comcast-to-send-its-own-copyrightalerts.

372. Andrew Wallenstein, Comcast Developing Anti-Piracy Alternative to 'Six Strikes', VARIETY (Aug. 5, 2013, 8:33 AM), http://variety.com/2013/digital/news/comcast-developing-anti-piracyalternative-to-six-strikes-exclusive-1200572790.

373. Id. 
result in the omission of positive evidence of graduated response's efficacy: given the resources that organizations such as the IFPI have put into advocating for graduated response, and the publicity they give to studies suggesting that it is achieving positive results, it is reasonable to expect that any such evidence would be widely published in English language materials and thus captured as part of this research project. Nevertheless, as the above analysis demonstrates, the evidence that graduated response actually reduces infringement is extraordinarily thin.

\section{B. To What Extent Do Graduated Responses MaXimize Authorized USES?}

The analysis now turns to the second aim of copyright law as identified in Part I of this Article-maximizing the size of the legitimate market. Again, this Article takes no position as to whether increasing the sales of industry incumbents is (or should be) one of copyright's aims. It simply evaluates the available evidence to gauge the extent to which graduated response does, in fact, increase the size of the legitimate market.

\section{The Danaher Study}

The most prominent evidence in support of this proposition is an academic study which found that Hadopi has had a positive impact on sales via Apple's iTunes service in France. ${ }^{374}$ That study has been widely cited as evidence of the efficacy of graduated response laws. ${ }^{375}$ The study was based on weekly iTunes sales data (split into singles and albums) for six European countries, including France, spanning the period between July 2008 and May 2011.376 France was the target of the study, and the other five countries were used as a control group. The researchers used Google Trends data to measure the percentage of all French searches that were for the term "HADOPI" over the same period, and graphed that data against the sales timeline. ${ }^{377}$ The graph, extracted below, demonstrates that French sales diverge from and remain above those of the control group. ${ }^{378}$ It also

374. Brett Danaher, Michael D. Smith, Rahul Telang \& Siwen Chen, The Effect of Graduated Response Anti-Piracy Laws on Music Sales: Evidence from an Event Study in France, J. INDUS. ECoN. (forthcoming 2014), available at http://papers.ssrn.com/sol3/papers.cfm?abstract_id=1989240.

375. See David J. Brennan, Quelling P2P Infringement-Private American Harbours or Public French Graduations?, 62 TeleComM. J. Austl. 55.1, 55.10-.11 (2012); John Hopewell \& Elsa Keslassy, World Watches as Gaul Rethinks Piracy, VARIETY, Jul. 23-29, 2012, at 4, 9; Eric Pfanner, A Piracy Law in France Appears to Curb File-Sharing and Lift Digital Music, N.Y. TIMES, Feb. 19, 2012, at B3; Joshua P. Friedlander, The Evidence of Anti-Piracy's Impact Continues to Mount, RECORDING INDUS. Ass'N OF AM. (Apr. 12, 2012), http://www.riaa.com/blog.php?content_selector=riaa-news-blog \&blog_selector=Mount\&news_month_filter=4\&news_year_filter $=2012$.

376. Danaher et al., supra note 374 , at 8 .

377. Id. at $9-11$.

378. Glyn Moody, iPhone Data Debunks Recording Industry's Report on how French Three Strikes Law Increased Sales, TECHDIRT (Feb. 1, 2012, 3:03 PM), http://www.techdirt.com/articles/ 20120131/06152417600/iphone-data-debunks-recording-industrys-report-how-french-three-strikes-lawincreased-sales.shtml. 
shows several sales spikes that roughly correspond to spikes in searches for "HADOPI." The divergence of French sales from those of the control group begins soon before the bulk of the queries. ${ }^{379}$

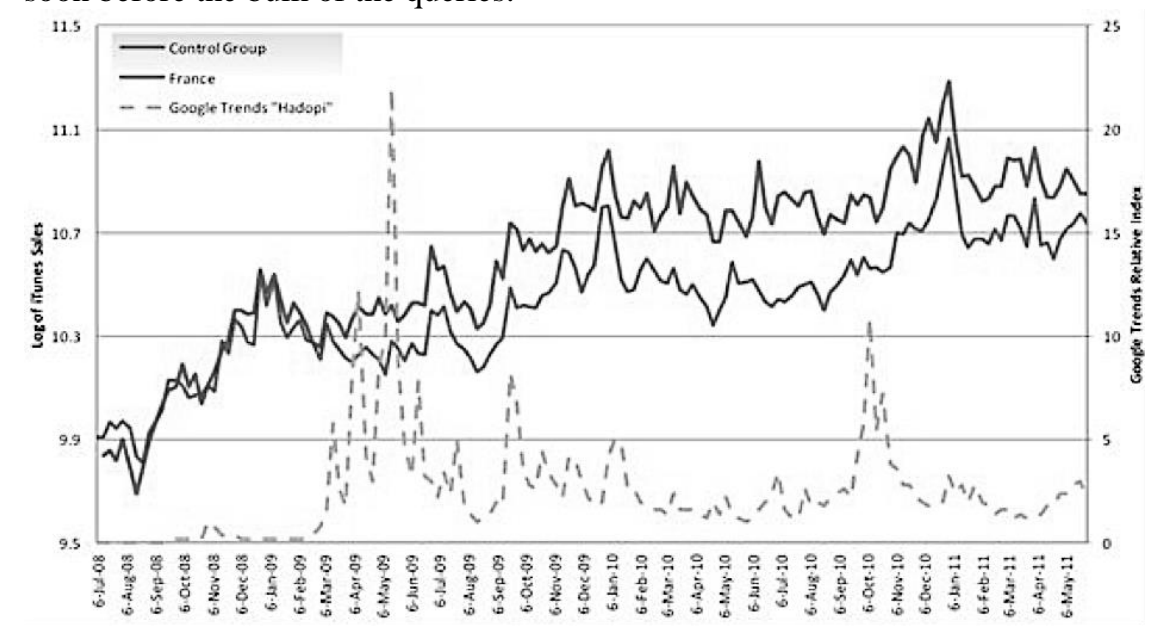

Diagram 1. Source: Le Monde. ${ }^{380}$ Originally published in the Danaher study. ${ }^{381}$

The study notes that iTunes track sales "rose about $25.5 \%$ in the control group after March 1, 2009 but by 48\% in France;" album sales "rose by $42 \%$ in the control group but $67 \%$ in France." 382 From this, the researchers concluded that "French iTunes track sales were $22.5 \%$ higher than they would have been in the absence of HADOPI" and that "HADOPI increased iTunes album sales an average 25\% per week in France." 383

The study's methodology and results have been criticized. French newspaper $L e$ Monde replicated the study, but, in recognition of the fact that iTunes is the dominant source of legitimate content for iPhone devices, it replaced the word "HADOPI" with the word "iPhone." It then compared the album sales in France and the control countries against Google search data for "iPhone" in France, "iPhone" in the control group, and "HADOPI" in France, showing that French user searches for "iPhone" also diverged from those of the control group. The resulting graph seemed to show a far more powerful correlation between the iTunes sales and French users' Google searches for "iPhone" than for searches for "HADOPI." Le Monde argued that this provided an alternative explanation for the increased sales: iTunes sales increased more strongly in France because user interest in

379. Danaher et al., supra note 374, at 13.

380. Damien Leloup \& Jérémie Baruch, Hadopi, source de la croissance d'iTunes?, LE MONDE (Jan. 24, 2012, 7:39 PM), http://www.lemonde.fr/technologies/article/2012/01/24/hadopi-source-de-lacroissance-d-itunes_1633919_651865.html.

381. Danaher et al., supra note 374, at 13. (Note that colors have been greyed. For reference purposes, "control group" is the higher solid line on 6-Jul-08 and the lower on 6-Apr-09.)

382. Id. at 14

383. Id. 
iPhones increased more strongly in France.

\section{Les ventes d'albums sur iTunes (en milliers)}

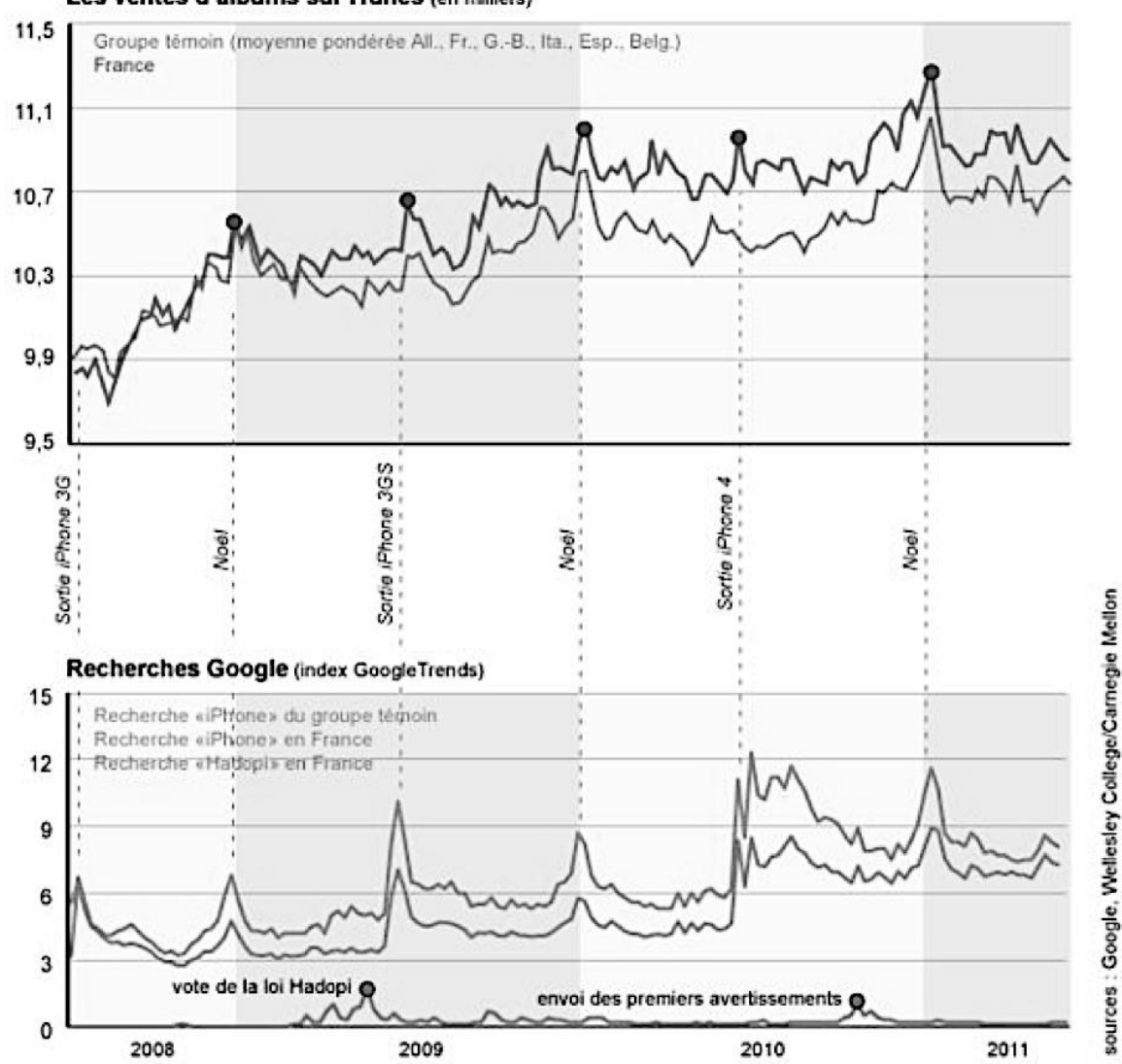

Diagram 2. Source: Le Monde. ${ }^{384}$

The authors of the Danaher study responded to the Le Monde critique by releasing a new graph which plotted "iPhone" searches in France against those in the control countries, stating that it "seems to show that searches for the term 'iPhone' in France do not significantly diverge from the normalized levels of searches in our control group countries," and concluding that, "based on the best data we have, we continue to believe that HADOPI provides the most reasonable explanation for the increase in French sales we observe and the disproportionate increase in sales of highly pirated genres." 385 Despite the criticisms of the study's

384. Leloup \& Baruch, supra note 385. (Note that colors have been greyed. For reference purposes, in the "Recherches Google" chart, "Recherche 'iPhone' du groupe témoin" is the consistently highest line and "Recherche 'Hadopi' en France" is the consistently lowest line.)

385. The researchers' response to the Le Monde criticisms is available at Brett Danaher, Michael D. Smith \& Rahul Telang, Did HADOPI Cause an Increase in iTunes Music Sales in France?, INFOJUSTICE (Mar. 14, 2012), http://infojustice.org/archives/8891. 
methodology, it is clearly one of the most intellectually rigorous attempts to measure the impact of graduated response to date, and one of very few that has been peer reviewed (at time of writing, the paper is forthcoming in the Journal of Industrial Economics).

While the Danaher study's scientific approach is a welcome improvement to the overall standard of evidence, it is notable that the "Hadopi effect" it identified in iTunes sales does not appear to have been replicated in the broader recorded music market. In the first two full years after HADOPI was introduced, IFPI's data show that the French recorded music market dropped by $2.7 \%$ (2011) and $2.9 \%$ (2012). ${ }^{386}$ By comparison, in the two years prior, it fell by $1 \%$ (2009) and $3.1 \%$ (2010). ${ }^{387}$ If HADOPI was in fact causing big increases in the amount of music sold, confirmation might have been expected in the form of this slide being arrested. As these numbers show however, it actually averaged a higher decline across 2011-2012 than in the two previous years. In an interesting contrast, three of the control group countries identified in the Danaher study averaged smaller declines over 2011-2012 than in 2009-2010. ${ }^{388}$

As discussed above, an increase in the size of the legitimate market was one of the key aims of the French legislation. However, after considering all of the available evidence, including the Danaher study, the Lescure Report found that even if HADOPI had brought about some reduction in P2P infringement, traffic had overwhelmingly been diverted to other infringing sources rather than to the legitimate market. ${ }^{389}$ As discussed below, this was one of the key reasons for its recommendation to wind back the scheme.

\section{The Korean Experience}

Organizations such as the IFPI have sometimes linked graduated response in Korea to increases in legitimate markets. For example, in the Digital Music Report 2013, it claimed:

The enforcement programme has, over a period of years, helped the licensed digital marketplace in South Korea significantly. The country's music market grew by 65 per cent between 2007, when the measures were introduced, and 2011, while Korean repertoire has exploded in the region and abroad. The country has advanced from being 23rd largest market in the world in 2007 to the 11th in 2012. ${ }^{390}$

It is certainly the case that music revenues have increased and music and film

386. Int'l Fed'n Phonographic Indus., Recording Industry in Numbers: The Recorded Music Market in 201247 (2013) (on file with author).

387. Id.

388. Id. at 51, 57, 48. Italy averaged a $4.1 \%$ loss over 2011 and 2012, compared to a $7.9 \%$ average loss across 2009-2010; Spain averaged a $4.15 \%$ loss in 2011-2012, compared to a $16.8 \%$ average loss in 2009-2010, and Germany averaged a $2.4 \%$ loss in 2011-2012, compared to a $3.3 \%$ average loss in 2009-2010. Id.

389. Pierre Lescure, supra note 60 (specific discussion of the Danaher study occurs at 369-370).

390. Int'l Fed'n Phonographic Indus., supra note 6, at 30. 
piracy have decreased within Korea. ${ }^{391}$ However, there is no evidence that either outcome has been caused by Korea's graduated response law. There are other possible explanations, including the impact of other anti-piracy policies. As Hargreaves pointed out, South Korea introduced a variety of reforms seeking to reduce infringement—not just graduated response - and he found that "[f]urther study would be needed to understand the relative merits of the different aspects of the programme." 392 The increased availability of legitimate options might also explain the piracy decrease. ${ }^{393}$ Yet another possible explanation is the huge rise in the popularity of the "K-Pop" genre. ${ }^{394}$ Notably, the IFPI responded to the calls to repeal the Korean graduated response by suggesting that the legislative environment, including the graduated response law and an extension of copyright terms to seventy years, actually "triggered the rejuvenation of ' $\mathrm{K}$-pop' music in South Korea and other Asian markets." 395 However, it provided no evidence of any causal link in support of this claim.

\section{To What Extent Does Changed Behavior Reflect Transitions to Other Sources of Infringement?}

To the extent, if any, that graduated response results in reduced infringement, it is necessary to ask: to what extent does it merely reflect a shift to other infringing sources? As noted above, switches to sources of infringement that fall outside the various graduated responses are another possible explanation for apparent reductions of infringement.

Hadopi is aware of this possibility, and its report on the law's first eighteen months of operation claimed that there had been no "substantial transfer" to illicit streaming and direct download services over the relevant period. ${ }^{396}$ However, considerable data contradicts that claim. For example, France was identified as the fifth fastest growing file sharing market in a study tracking BitTorrent usage data for the first half of 2012.397 While BitTorrent has significant and growing noninfringing uses, it is often used as a proxy for measuring infringement. In addition,

391. See e.g., HARGREAVES, supra note 355.

392. Id.

393. IFPI discusses the increase in legitimate services in its response to a proposal to repeal the South Korean graduated response law. See Int'1 Fed'n Phonographic Indus., IFPI Comments on the Amendment of the Copyright Act in Relation to the Graduated Response Regime in the Republic of Korea 3-4 (Mar. 2013), http://opennet.or.kr/wp-content/uploads/2013/04/IFPI-Comments-onAmendment-of-Copyright-Act-in-relation-to-GR-inSouth-Korea.pdf.

394. South Korea Continues to Develop as a Model for Future Recorded-Music Markets, MUSIC \& COPYRIGHT's BLOG (Mar. 10, 2011), http://musicandcopyright.wordpress.com/2011/03/10/south-koreacontinues-to-develop-as-a-model-for-future-recorded-music-markets.

395. Int'l Fed'n Phonographic Indus., IFPI Comments on the Amendment of the Copyright Act in Relation to the Graduated Response Regime in the Republic of Korea 1-2 (Mar. 2013), http://opennet.or. $\mathrm{kr}$ /wp-content/uploads/2013/04/IFPI-Comments-on-Amendment-of-Copyright-Act-in-relation-to-GRinSouth-Korea.pdf.

396. HAUTE AUTORITE, supra note 296, at 7.

397. Digital Music Index, MusicMetric1, at 38 (Sept. 2012); see also id. at 5 (explaining the scope of the study). 
France Telecom reportedly noticed "a dramatic increase in streaming traffic" and "a marked increase in levels of encrypted traffic" shortly after HADOPI came into effect. ${ }^{398}$ An independent study conducted by researchers at the University of Rennes carried out soon before Hadopi began issuing notices found that the law was redirecting infringement to non-P2P technologies like streaming sites and cyberlockers. ${ }^{399}$ Conducted via a phone poll of two thousand participants between November and December 2009, the survey found an overall 3\% increase in the amount of infringing behavior. ${ }^{400}$ Survey data has obvious limitations, especially with small sample sizes. However, it further suggests that users were engaging in antiregulatory behavior falling outside the operation of the law, whilst facilitating exactly the same end result. As noted above, after considering the available evidence, the Lescure Report also found that even if HADOPI had brought about some reduction in P2P infringement, traffic had been diverted to other infringing sources rather than to the legitimate market. ${ }^{401}$ This finding significantly drove Lescure's conclusion that HADOPI had not achieved the aim identified in the Olivennes Report, i.e. increasing the size of the legitimate market. ${ }^{402}$

There is also evidence that the law is driving antiregulatory activity in New Zealand. Because the New Zealand scheme applies only to file sharing via P2P networks, it can be simply bypassed by switching to other tools for infringement. ${ }^{403}$ These include distributed online discussion systems like Usenet, and "cyberlockers," or online file hosting sites. Both of these technologies enable the storage and transfer of large files via a client server rather than "peer-to-peer" network architecture. Users may also use technologies such as VPNs, remote access protocols and "seedboxes" to distance themselves from P2P infringement. Seedboxes are high-speed remote servers, typically hosted in jurisdictions with less stringent copyright laws than the subscriber's home jurisdiction. Users can download desired content directly to the seedbox via BitTorrent, and then transfer it to their own computer via a HTTP or, more securely, a HTTPS connection. ${ }^{404}$ In exchange for a small monthly fee, this enables users to obtain content via P2P networks while falling outside the graduated response law.

Discussions on public online fora indicate that New Zealanders are very aware of what they need to do to fall outside the law while achieving the same infringing

398. Monica Horten, Hadopi-Has it Massaged the Numbers?, IPTEGRITY (Mar. 31, 2012), http://www.iptegrity.com/index.php/france/755-hadopi-has-it-massaged-the-numbers.

399. Sylvain DeJean, Thierry Penard \& RaphaËl Suire, Une premiere eValuation des EFFETS DE LA LOI HADOPI SUR LES PRATIQUES DES INTERNAUTES FRANÇAIS 11-12 (2010), http://recherche.telecom-bretagne.eu/marsouin/IMG/pdf/NoteHadopix.pdf.

400. Id.

401. See Lescure, supra note 60, at 371.

402. Id.

403. For a more comprehensive discussion on the New Zealand law, see Giblin, On the (New) New Zealand Graduated Response Law (and Why It's Unlikely to Achieve Its Aims), supra note 85.

404. For an introduction to seedbox technology, see Sharky, Speed Up Your Torrent Downloads, Get a Seedbox, TORRENTFREAK (Jul. 15, 2008), http://torrentfreak.com/10-reasons-why-you-need-aseedbox-080715. 
results. Some typical comments include, "[p]eople I know appear to have switched to other means of obtaining the things they were interested in. They are still getting it. Just not via Bittorrent," 405 and "with that new law in place, http downloads are the way to go if you want to stay below the radar."406 Indeed, the level of awareness is such that a newspaper article reporting the first decision under the New Zealand law ridiculed the individual concerned, suggesting that it was simply "digital Darwinism in action."407

The Waikato study referenced above found a significant jump in the use of technologies that could be used to circumvent the "three strikes" law (although that increase was less than the drop observed in the amount of file sharing). 408 The follow-up study found an enormous increase in the amount of HTTPS traffic, which the researchers theorized was probably

indicative of illegal file sharing moving to foreign seedboxes where the user can transfer the files back to their home computer using HTTPS. The corresponding increase in VPN and remote access protocols appear to corroborate this, as these protocols would be used to access and configure seedboxes. ${ }^{409}$

Of course, anything that makes it more difficult to commit infringement has the potential to stop people from engaging in it-but that does not necessarily mean that it is driving infringers to the legitimate market. As this analysis has demonstrated, there is little persuasive evidence showing a causal link between graduated response and increased legitimate usage.

\section{To What Extent do Graduated Responses Promote Learning And Culture by Encouraging The Creation AND Dissemination OF A Wide VARIETy OF CREATIVE MATERIAls?}

The central tenet of the utilitarian rationale for copyright is that it is necessary to promote broad public interest aims, such as the spread of knowledge and culture, by encouraging the creation and dissemination of a wide variety of creative materials. ${ }^{410}$ Thus, "[a] marketable right is conferred to ensure a sufficient supply

405. LinuxLuver, Comment to Keen to Hear from Anyone that Receives a Copyright Infringement Notice, GEEKZONE (Sept. 5, 2011, 2:12 PM), http://www.geekzone.co.nz/forums.asp?forumid=49\& topicid $=89556$.

406. Paulfknwalsh, Comment to Netflix Rules Out New Zealand Launch-Broadband Too Slow, Can't Get Content Rights, REDDIT (Nov. 28, 2011), http://www.reddit.com/r/newzealand/comments/ msrsj/netflix_rules_out_new_zealand_launch_broadband/c331xb7.

407. Pat Pilcher, Is Skynet Really Digital Darwinism in Action?, N.Z. HERALD (Feb. 4, 2013 1:45 PM), http://www.nzherald.co.nz/business/news/article.cfm?c_id=3\&objectid=10863328.

408. ALCOCK \& NELSON, supra note 347.

409. The Impact of the Copyright Amendment Act: Update for September 2012, WAND NETWORK RES. GRP. (Oct. 25, 2012), http://wand.cs.waikato.ac.nz/content/impact-copyrightamendment-act-update-september-2012.

410. See, e.g., H.R. REP. NO. 60-2222, at 7 (1909) ("The enactment of copyright legislation by Congress under the terms of the Constitution is not based upon any natural right that the author has in his writings . . . but upon the ground that the welfare of the public will be served and progress of science and useful arts will be promoted by securing to authors for limited periods the exclusive rights to their 
of disseminated knowledge and information," and "[c]opyright protection can only be justified and is only to be conceded insofar as it can be deemed beneficial for society as a whole." 411 In the words of the Supreme Court of the United States, copyright "reflects a balance of competing claims upon the public interest: Creative work is to be encouraged and rewarded, but private motivation must ultimately serve the cause of promoting broad public availability of literature, music, and the other arts." ${ }^{\prime 12}$ Even in France, a country with a strong natural rights tradition, the Government has made it clear that the role of culture in the personal development of individuals means that it is "too important to leave cultural productions fully subject to the law of the market. The intervention of the public authorities is necessary to ensure the survival of a rich cultural offer, varied and accessible to the greatest number." ${ }^{413}$

This section seeks to evaluate the extent to which existing graduated response regimes promote the spread of learning and culture by asking: (1) To what extent do graduated response regimes promote the creation of a wide variety of creative works? And (2) To what extent do such regimes actively encourage widespread dissemination of content?

\section{To What Extent Do Graduated Response Regimes Promote the Creation of a Wide Variety of Creative Works?}

The above analysis has concluded that there is little evidence that graduated response laws reduce infringement or increase the size of the legitimate market. If that is the case, it may well be that graduated response plays no role in encouraging the creation of new works. However, if such laws do have a positive effect on content creation, it appears that they are likely to disproportionately encourage the development of a certain kind of content and production model.

An under-recognized feature of many existing graduated responses is that their design ensures that not all content (or content owners) are treated equally. When copyright policy is being formulated, many copyright owners do not claim a seat at the negotiating table. There are many possible reasons for this, including that their interests are too diverse, that they lack organization and resources or that they are not concerned enough by copyright to get involved. By contrast, the entities comprising "Big Content"- the movie and music conglomerates largely spearheaded by the MPAA and RIAA - have shared interests, are highly organized and have copyright at the core of their businesses. It is unsurprising, then, that they play a disproportionately large role in international copyright policymaking. Their

\footnotetext{
writings."); SenFtleben, supra note 14, at 7, 13; PAUl GoldSTEIN, GOLDSTEIN ON COPYRIGHT $\S 1.13 .2$ (3d ed. 2005).

411. SENFTLEBEN, supra note 14 , at 7, 13.

412. Twentieth Century Music Corp. v. Aiken, 422 U.S. 151, 156 (1975) (internal notes omitted).

413. Culture-acte 2: 80 propositions sur les contenus culturels numériques, MINISTERE DE LA CUlTURE ET DE LA COMMUNICATION (May 10, 2013), http://www.culturecommunication.gouv.fr/ Actualites/A-la-une/Culture-acte-2-80-propositions-sur-les-contenus-culturels-numeriques (wording of quotation via Google Translate).
} 
influence permeates many of the graduated response regimes operating today.

For example, the only content owners who are entitled to issue notices under the Irish scheme are the parties to the settlement, i.e., the Irish branches of EMI Records, Sony BMG Music Entertainment, Universal Music and Warner Music. The private scheme operating in the U.S. is rather more inclusive: it not only permits the MPAA and RIAA to protect their members' interests, but also the Independent Film and Television Alliance (whose members produce more than four hundred films per year ${ }^{414}$ ) and the American Association of Independent Music (which currently represents over two hundred independent labels). ${ }^{415}$ However, creators and rights holders outside these organizations are unable to take advantage of these mechanisms to protect their content.

A number of the statutory schemes also exhibit structural biases in favor of the biggest rights holders. The New Zealand scheme is one example. As explained above, the New Zealand law only permits enforcement action to be instituted against an account holder once three complying infringement notices relating to the same rights holder have been issued. This means that an account holder could theoretically receive dozens of infringement notices from multiple rights holders without any one of them accruing the right to take enforcement action. However, the law also allows rights holders to "pool" infringements, by defining a "rights owner" as being either "a copyright owner" or "a person acting as agent for 1 or more copyright owners." 416 This broad definition of "rights owner" was advocated by the Select Committee tasked with reviewing the legislation. The Committee explained that it would permit "enforcement action [to] be taken against an account holder who had received three notices of recording infringements relating to three sound recordings by three different copyright owners, provided that those owners had previously decided to be represented as a group in enforcing their rights."417

That pooling arrangement makes it disproportionately difficult for smaller, less established or independent rights holders to reach the enforcement stage. This may at least partly explain why none appear to have done so. Instead, in almost two years of operation, RIANZ appears to be the only organization that has issued any notices at all under the New Zealand law. As of August 2013, thirteen cases have been decided. In each, RIANZ has acted as agent for major labels such as Universal, Sony and EMI. Every case has involved infringements of music performed by international artists such as Beyoncé, Coldplay and Elton John. Not a single local New Zealand artist has been featured. This can be at least partly

414. Jean Prewitt, IFTA Comments to Voluntary Best Practices Study 1 (Jul. 22, 2013), in U.S. Patent and TRademark OfFice, Comments Regarding USPTO's JoInt StRategic Plan for INTELLECTUAL PROPERTY ENFORCEMENT VOLUNTARY BeST PRACTICES STUDY, available at http://www.uspto.gov/ip/officechiefecon/PTO-C-2013-0036.pdf\#page=6 (emphasis added).

415. Label Members, AM. AsSOC. OF INDEP. MuSIC, http://a2im.org/contents/?taxonomy=c _ sitewide_group\&term=label (last visited Nov. 16, 2013).

416. Section 122A of the Copyright Act 1994 (N.Z.).

417. Commerce Committee, Copyright (INFringing File Sharing) AMENDMENT BiLl: COMMENTARY 3-4 (2010) (N.Z.), available at http://www.legislation.govt.nz/bill/government/2010/ 0119/latest/096be8ed8063b81d.pdf. 
explained by the fact that the biggest international artists are most likely to attract the most interest from illegal downloaders, and thus have a greater chance of detection. However, the clear message is that infringers are only at risk if they step on the toes of powerful international rights holders. Other content owners and creators, who may also be facing serious challenges from widespread infringement, effectively receive less protection than Big Content.

The UK regime has also been designed in a way that risks disproportionately benefiting the largest rights holders. As noted above, only those copyright owners who have provided written estimates of the number of notifications they are likely to make in the following year, well in advance, to each qualifying ISP and to Ofcom, will be permitted to utilize the system. ${ }^{418}$ Additionally, those copyright owners must obtain pre-approval of their evidence gathering procedures from Ofcom. In practice, these requirements are likely to limit the scheme's operation to the largest music, movie and publishing houses, and not to smaller content providers who are also impacted by large scale infringement. Ofcom noted that this argument had been raised during the consultative process: "[s]ome copyright owners . . . suggested that the requirement for up-front estimates . . . could mean that some copyright owners - notably SMEs [small to medium enterprises] - could be prevented from participation in the notification regime for administrative and financial reasons." 419 Recognizing the merits of this argument, Ofcom responded by suggesting that

it may be possible for SME operators to engage with trade bodies which indicate they are likely to make commitments to CIR [copyright infringement report] volumes, and either join them at the beginning of a notification period, or even assume responsibility for some of their CIR estimates during a notification period. By aggregating uncertain demand across participants, such agencies may be able to make up-front commitments which make it easier for SME members to participate. ${ }^{420}$

However, since smaller operators lack the organizational and financial resources of organizations such as the MPAA and RIAA, it is doubtful whether this will occur in practice.

Although there is less evidence of structural bias in other jurisdictions, there is evidence of heavy involvement on behalf of powerful U.S.-based rights holders in each. Taiwan's implementation of a graduated response was cited as a key reason for its removal from the U.S. Trade Representative's "special watch list" in 2009, in an unusual "out of cycle" review. ${ }^{421}$ Korea was also removed from the list the same year-it was the first time in the list's history in which Korea did not

418. Off. Comm., Online Infringement of Copyright and the Digital Economy Act 2010: Notice of Ofcom's Proposal to Make by Order a Code for Regulating the Initial Obligations, at 18 (Jun. 26, 2012), http://stakeholders.ofcom.org.uk/binaries/consultations/online-notice/summary/notice.pdf.

419. Id. at 19.

420. Id.

421. Press Release, Office of the U.S. Trade Representative, U.S.T.R. Announces Conclusion of the Special 301 Out-of-Cycle Review for Taiwan (Jan. 2009), http://www.ustr.gov/about-us/pressoffice/press-releases/2009/january/ustr-announces-conclusion-special-301-out-cycle-re. 
appear. $^{422}$ Korea's approach may also have been influenced by obligations under its "free trade" agreement with the U.S. ${ }^{423}$ The agreement included a notable side letter which imposed unilateral obligations on South Korea to "provid[e] for more effective enforcement of intellectual property rights on the Internet, including in particular with regard to peer-to-peer (P2P) services," followed by a promise to "strengthen enforcement of intellectual property rights in Korea, and work to prevent, investigate, and prosecute Internet piracy." 424 In France, it is notable that two of the three convictions related to artists signed to U.S. labels (Universal and Warner Music). ${ }^{425}$ On this point, it is also worth mentioning some Australian history. Australia does not currently have a graduated response, but an attempt was made to introduce one via the common law. ${ }^{426}$ Although the effort was ostensibly headlined by a local organization, leaked diplomatic cables demonstrated that the MPAA was the real driving force behind the litigation. ${ }^{427}$

As this Article has demonstrated, there is little evidence that graduated response does anything to reduce infringement or increase the size of the legitimate market. If it did achieve those things, however, the structural biases identified within the various regimes suggest that they would disproportionately favor a particular kind of content - that created by the largest and most powerful rights holders. Regulators ought to give careful consideration to whether this is the kind of content creation they most wish to incentivize, and whether they want to do so at the expense of independent and other less established creators. In the digital world, is the most desirable creativity still necessarily that which costs the most to produce?

\section{To What Extent Do Graduated Response Laws Actively Encourage Widespread Dissemination of Content?}

A number of jurisdictions have made it explicitly clear that they intended their graduated response laws to encourage legitimate uptake. For example, the New Zealand scheme seeks to ensure that creative industries "adapt to changing

422. 2009 Special 301 Report, OfF. U.S. TRADE REP., Apr. 30, 2009, at 10, available at http:// www.ustr.gov/sites/default/files/Full\%20Version\%20of\%20the\%202009\%20SPECIAL\%20301\%20RE PORT.pdf.

423. See Free Trade Agreement between the United States of America and the Republic of Korea, U.S.-S. Kor., June 30, 2007. The full text of the KORUS free trade agreement is available at http:// www.ustr.gov/trade-agreements/free-trade-agreements/korus-fta/final-text.

424. Letter from Hyun Chong Kim, Minister for Trade, Republic of Korea, to Susan C. Schwab, United States Trade Representative (June 30, 2007), available at http://www.ustr.gov/sites/default/files/ uploads/agreements/fta/korus/asset_upload_file939_12739.pdf.

425. See discussion supra Part II.A.1.b.

426. See Giblin, Was the High Court in iiNet Right to Be Chary of a Common Law Graduated Response?, supra note 360.

427. See, e.g., Cable attributed to Robert D. McCallum, Cable 08CANBERRA1197, FILM/TV INDUSTRY FILES COPYRIGHT CASE AGAINST, WIKILEAKS (Nov. 30, 2008 11:13 PM), http://wikileaks.org/cable/2008/11/08CANBERRA1197.html (stating that the Australian Federation Against Copyright Theft was acting "on behalf of the Motion Picture Association of America (MPAA) and its international affiliate, the Motion Picture Association (MPA), but d[id] not want that fact to be broadcasted"). 
technologies and the changing market place for creative works." 428 In the UK legislation's second reading speech, the moving Minister stated that the Act was intended to provide "a proper legal framework to tackle unlawful downloading" in order to achieve the aim of "developing legitimate paid-for downloading models," and anticipated that, in response to receiving notices, the "vast majority of subscribers will seek legal alternatives." 429 A statement welcoming the agreement that paved the way for the U.S.'s private graduated response stated that "[t]he Administration is committed to reducing infringement of American intellectual property as part of our ongoing commitment to support jobs, increase exports and maintain our global competitiveness." 430 In France, the report that provided the HADOPI framework emphasized that the intent was not simply to reduce infringement, but to translate that reduction into increased legitimate consumption. ${ }^{431}$

Sometimes, the introduction of graduated response seems to have led, if not to increased legitimate consumption, then at least to an increase in the amount of legitimate offerings available. For example, in Ireland, Eircom's introduction of the suspension scheme occurred simultaneously with its launch of a legal music service, ${ }^{432}$ suggesting that the latter was driven and enabled by the former. ${ }^{433}$ And the number of legitimate music services quickly doubled in the months after New Zealand rolled out its graduated response, ${ }^{434}$ with RIANZ claiming that "[m]any had been encouraged to launch because of the crackdown on piracy." 435 So it does appear that introducing graduated response can lead to an increase of legitimate offerings. But to what extent are the various schemes structurally designed to require or encourage an increase in the number of available services, or to improve their attractiveness to consumers?

The French scheme is the clearest example of an attempt to entice rights holders to offer better access in exchange for more enforcement. As noted above, the Olivennes Report provided the framework and rationales for the HADOPI

\footnotetext{
428. [2011] 671 NZPD 18083 (N.Z.).

429. 508 PARL. DEB., H.C. (6th ser.) (2010) 839-40 (U.K.).

430. Victoria Espinel, Working Together to Stop Internet Piracy, The White House BLoG (July 7 , 2011, 12:15 PM), http://www.whitehouse.gov/blog/2011/07/07/working-together-stop-internet-piracy.

431. DENIS OLIVENNES, LE DEVELOPPEMENT ET LA PROTECTION DES OEUVRES CULTURELLES SUR LES NOUVEAUX RESEAUX: RAPPORT AU MiNISTERE DE LA CULTURE ET DE LA COMMUNICATION 9-11 (Nov. 2007), available at http://www.culture.gouv.fr/culture/actualites/conferen/albanel/ rapportolivennes231107.pdf.

432. Press Release, eircom, eircom Statement on Illegal File Sharing (Dec. 8, 2010), http://press room.eircom.net/press_releases/article/eircom_Statement_on_Illegal_File_Sharing.

433. Internet Society, Perspectives on Policy Responses to Online Copyright Infringement: An Evolving Policy Landscape 23 (Feb. 20, 2011), http://www.wipo.int/edocs/mdocs/copyright/en/wipo_ isoc_ge_11/wipo_isoc_ge_11_ref_00_runnegar.pdf.

434. Recording Indus. Ass'n of N.Z., supra note 317, para. 5.

435. Tom Pullar-Strecker, Four in 10 Kiwis Still Flout Piracy Laws, STUFF.CO.NZ (Jul. 23, 2012, 5:00 AM), http://www.stuff.co.nz/technology/digital-living/7318453/Four-in-10-Kiwis-still-flout-piracy -laws.
} 
legislation. ${ }^{436}$ The Report subsequently evolved into a formal agreement between the Government and some forty-five stakeholders representing the largest content interests ("the Olivennes Agreement"). ${ }^{437}$ The agreement provided for the Government to enact the three strikes enforcement program as envisaged in the Olivennes Report, in exchange for a range of concessions from content providers, including obligations to: (1) shorten release windows for audio-visual content, and align "video on demand" releases with the physical (i.e. DVD) releases; (2) work towards faster online film releases; (3) make "best efforts" to make video content available online after broadcast; and (4) make French music available without technical protection measures within a year of the agreement. ${ }^{438}$

Although some of these targets were aspirational rather than binding, they all shared the same focus on encouraging the widest possible dissemination of legitimate content. More recently, the Lescure Report recommended shortening release windows even further. ${ }^{439}$ Notably, these windows are set by law in France, rather than left as a matter of private agreement. ${ }^{440}$ Since 2009, under the deal struck as part of the Olivennes Agreement, movies are required to be released on physical media and video-on-demand four months after theatrical release. ${ }^{441}$ The Lescure Report recommends a further reduction to three months. ${ }^{442}$

No other jurisdiction has so expressly encouraged broader dissemination or more attractive offerings by extracting it as a price to be paid in exchange for greater enforcement rights. However, various stakeholders have argued strongly in favor of doing so in New Zealand. For example, Greens MP Gareth Hughes argued for "a zero-dollar penalty for infringing against international products that are not available in New Zealand" on the basis that it "may have encouraged rights-holders to provide digital content sooner to Kiwis." 443 InternetNZ proposed linking availability of content to availability of substantial damages. If a work was not available for sale in New Zealand at the time of the infringement, it proposed that the copyright owner should only be entitled to its reasonable costs of enforcement. ${ }^{444}$ None of these proposals were adopted, and if the aim of the legislation is to promote the broadest dissemination of content, this can be seen as

436. See Olivennes, supra note 431.

437. Accord pour le développement et la protection des ouvres et programmes culturels sur les nouveaux réseaux, MiNisTERE DE LA CULTURE ET DE LA COMMUNICATION (Nov. 23, 2007), http://www. culture.gouv.fr/culture/actualites/conferen/albanel/accordolivennes.htm. The signatories to the agreement are published at www.culture.gouv.fr/culture/actualites/conferen/albanel/organisations signataires.pdf.

438. Olivennes, supra note 431, at 9-11.

439. Lescure, supra note 60, at 96-97.

440. See id. at 89 .

441. Id. at 96 .

442. Id. at 96-97.

443. [2011] 671 NZPD 18090 (N.Z.).

444. InternetNZ, Submission to the Ministry of Economic Development on the Copyright (Infringing File Sharing) Regulations 2011 Discussion Document, para. 31.3 (May 27, 2011), available at http://internetnz.net.nz/system/files/submissions/submission_to_the_med_on_the_copyright_ infirnging_file_sharing_regulations_2011_discussion_document.pdf. 
an opportunity lost. New Zealand is "at the end of U.S. or European-based supply chains ... [and] can wait months or sometimes years to get access to content that is freely available overseas." 445 Prices paid by New Zealanders for digital content can also be considerably higher than for identical content purchased overseas. ${ }^{446}$ And in an additional blow, popular U.S.-based video streamer Netflix ruled out a New Zealand launch partly because it was unable to clear the necessary rights. ${ }^{447}$ As designed, the New Zealand law appears to do little to expressly promote its stated aim of ensuring that creative industries "adapt to changing technologies and the changing market place for creative works." 448 Instead, rights holders are left to provide content in the manner they see fit, without consideration of whether their motivations align with the broader public interest.

It may be that the regulators tasked with designing the existing graduated responses assumed that they would reduce infringement, and that reduced infringement would lead inevitably to the fulfillment of copyright's broader aim of encouraging the creation and dissemination of a wide variety of cultural artifacts. This would explain why, with the exception of the French law, the structural designs of the various regimes provide so little in the way of express incentives to make content more broadly available. The above analysis has demonstrated, however, that graduated responses actually do little to incentivize the widest possible creation and dissemination of content. In many cases, such responses encourage the creation of Big Content more than other forms, suggesting that they are not designed to motivate the widest possible creative production. However, given the lack of evidence that graduated response does anything to reduce infringement or increase legitimate markets, these structural biases in favor of Big Content may have little or no effect in practice.

\section{CONCLUSION}

Graduated response schemes have been variously criticized for impinging on the human right to freedom of expression, for breaching privacy and for failing to comply with key tenets of the rule of law. ${ }^{449}$ But quite separate from those criticisms, their legitimacy is seriously thrown into question by the startling lack of evidence that graduated response helps achieve any of copyright law's underlying aims.

Powerful rights holders have repeatedly claimed that graduated responses are "effective" and "successful." 450 By using headlines like "The Evidence of Anti-

445. [2011] 671 NZPD 18090 (N.Z.).

446. Claire Rogers, Online purchases 'a rip-off,' STUFF.CO.NZ (Sept. 26, 2011, 5:00 AM), http://

www.stuff.co.nz/technology/digital-living/5681610/Online-purchases-a-rip-off.

447. Natalie Apostolou, Netflix Rules Out Kiwi Launch, THE Register (Nov. 28, 2011), http://www.theregister.co.uk/2011/11/28/netflix_says_no_to_nz.

448. [2011] 671 NZPD 18083 (N.Z.).

449. See supra text accompanying note 290.

450. See supra Part I. 
Piracy's Impact Continues to Mount,"451 they continually send messages that graduated response laws work as promised. Evaluating the "success" or "effectiveness" of graduated response is undoubtedly a difficult exercise. Not only is there fundamental disagreement about the measures that they should be judged against, but, as Hargreaves has pointed out, although "online infringement of copyright and the measures used to combat it are well established phenomena, there is relatively little research evaluating the impact of specific approaches." 452 Despite those difficulties, this Article's analysis has demonstrated that the claims made about the success of the global graduated response are not supported by the available evidence.

There is no evidence demonstrating a causal connection between graduated response and reduced infringement. If "effectiveness" means reducing infringement, then graduated response is not effective. Furthermore, there is little convincing evidence that any variety of graduated response increases the size of the legitimate market. The Danaher study is the best attempt at doing so, but its findings have not been replicated across the broader recorded music market, and after carefully considering the larger picture against all available evidence, the Lescure Report concluded that HADOPI was not in fact increasing the legitimate market. There is no other evidence claiming a causal link between increased legitimate sales and graduated response in France, and none at all in other jurisdictions. Thus, if "effectiveness" means increasing the market, then graduated response has not been demonstrated to be effective.

What about the third aim? Do graduated responses encourage the widest possible production and dissemination of a variety of cultural content? Some graduated response schemes might. France, at least, has required rights holders to provide some content carrots in exchange for their new enforcement sticks, though as there do not appear to have been any attempts to measure the practical effect of this policy, there is no proof that it has worked as intended. Overwhelmingly, however, graduated responses do very little to actively require or even encourage beneficiaries to make more content than they otherwise would, or to distribute it more widely. Regulators have left rights holders almost unfettered discretion as to how to distribute their works - and it is not surprising that they do so in ways that maximize their profits, rather than in pursuit of copyright's wider public interest aims. Furthermore, existing graduated response regimes don't necessarily emphasize the production and dissemination of a "wide variety" of content. As demonstrated, a number of schemes disproportionately incentivize the creation and dissemination of Big Content over independent and smaller-budgeted forms of creation. Nevertheless, in the absence of evidence that graduated response reduces infringement or increases legitimate markets, it is highly unlikely that it incentivizes even the creation of more Big Content than would otherwise be created. In sum, there is precious little evidence that graduated response is

451. Friedlander, supra note 375.

452. HARGREAVES, supra note 355 , at 77. 
effective on any measure.

News is good in content markets worldwide. IFPI recently reported that the global music industry "has achieved its best year-on-year performance since 1998." 453 The movie industry has broken its record for worldwide box office receipts for the last seven years straight. ${ }^{454}$ A recent study found copyrightintensive industries to be significantly more profitable than their equivalents in the construction, transportation, mining and metals sectors. ${ }^{455}$ And there is growing evidence that new business models based on providing reasonable access to legitimate content are both reducing infringement and substantially increasing legitimate markets. ${ }^{456}$ But there is very little evidence that these outcomes have been caused by graduated responses. International regulators considering implementation of new graduated response schemes must be surer than ever to carefully consider the policy aims they wish to achieve, and to evaluate whether the proposals on the table would actually help to achieve them. And regulators who have already enacted graduated response laws should take a close look at the evidence and consider whether it is desirable to maintain them in their current forms. They might also consider encouraging or requiring those advocating for the schemes' retention to make relevant data available to researchers for rigorous, independent analysis, holding them to a higher standard of proof than has been accepted to date. Much can be done to design copyright law in ways that will help achieve desired aims. But as far as we can tell from the available evidence, the current global graduated responses overwhelmingly fail to do so.

453. Int'1 Fed'n Phonographic Indus., supra note 6, at 5.

454. See e.g., Nate Anderson, Piracy Once Again Fails to Get in Way of Record Box Office, ARS TECHNICA (Feb. 23, 2011, 4:06 PM), http://arstechnica.com/tech-policy/2011/02/piracy-once-againfails-to-get-in-way-of-record-box-office (providing the numbers for the period spanning 2006-2010); Motion Picture Assoc. Am., Theatrical Market Statistics 20112 (2012), available at http://www.mpaa.org/resources/5bec4ac9-a95e-443b-987b-bff6fb5455a9.pdf (providing the 2011 data); Global Box Office Reaches Record High in 2012, Motion Picture Assoc. of Am. (Mar. 21, 2013), available at http://www.mpaa.org/resources/43a3b102-6703-45f4-a15c-ac75573f4352.pdf (providing the 2012 data, the most recent available at time of writing).

455. Jonathan BAnd \& Jonathan Gerafi, Profitability of Copyright InTENSIVE INDUSTRIES 3 (Jun. 2013), available at http://infojustice.org/wp-content/uploads/2013/06/Profitabilityof-Copyright-Industries.pdf.

456. A comprehensive examination of this phenomenon has been undertaken in Giblin, Beyond Graduated Response, supra note *. See also ERICSSON, TV AND MEDIA 11 (Aug. 2013), available at www.ericsson.com/res/docs/2013/consumerlab/tv-and-media-consumerlab2013.pdf. 